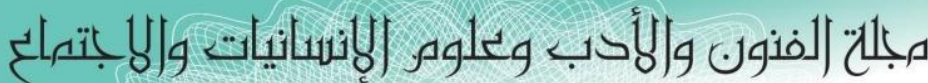

Journal of Arts, Literature, Humanities and Social Sciences

ISSN online: 2414 - 3383

ISSN print: 2616 - 3810

العدد (43) ايلول - سبتمبر 2019

\title{
المضمر في تصاميم الازياء الاعلانية المطبوعة رقميا
}

الاستاذ المساعد الاكتورة سهام محسن كيطان

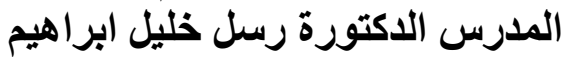

الجامعة التقنية الوسطى/ معهل الفنون التطبيقية/ قسم تقنيات التصميم الطباعي

بغذاد - العراق

الماخص

تتميز المطبو عات الرقمية بأمتلاكها عناصر التفرد في التنفيذ لكونها معالجة تقنياً على وفق البرامج التصميمية

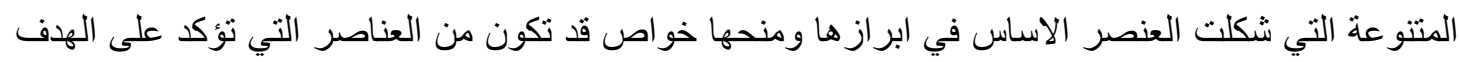
الذي وظفت لأجله تللك الاشكال ضمن المطبوعات وعلى اختلافها، ومن بين تللك المطبوعات اغلفة مجلات تتضمن اعلانات لأزياء تحمل بين طياتها معاني ومضامين متنوعة اعتماداً على ما توحي به من المعاني التي ولي تظهر في ذلك الاعلان، وعليه جاء البحث ليسلط الضوء على المضمر في تصاميم ازياء الاعلانات المصورة التي تتضمنها اغلفة المجلات، وقد تألف البحث من ثلاثة فصول تضمن الاول منهجية البحث المنمثلة بمشكلة البحث التي تم طرحها بالتساؤل الاتي: ماهو المضمر في تصاميم الازياء الاعلانية المطبوعة رقمياً؟ اما حدوده فقد تمثلت الحد الزماني للفترة من 2017-2018 و الحد المكاني المتمثل بمجلة فوغ العربية، و الحد الموضوعي لهي المضمر في تصاميم الازياء الاعلانية (المصورة على غلاف المجلة ) . . ، اما الفصل الثاني المتمثل بالاطار النظري الذي اعتمد على تناول الجانب النظري الذي يعزز البحث ويصب في موضوعه، وتناول الفصل الثالث اجر اءات البحث ونتائجه وتم تعزيز البحث بالاعتماد على المصادر التي تناولت موضوعات البحث اضافة الى مئ الملخص باللغة الانكليزية. 


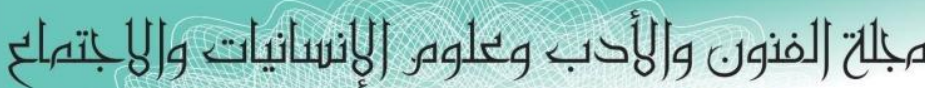

Journal of Arts, Literature, Humanities and Social Sciences

ISSN online: 2414 - 3383

ISSN print: 2616 - 3810

أيلول - سبتهبر 2019

الصدد (43)

\title{
The Inherent in Fashion Designs that are Digitally Printed
}

\author{
Assistant Professor Dr. Seham Muhsen Getan \\ Dr. Russell Khalil Ibrahim \\ University of Technical Technology / Institute of Applied Arts / Department of \\ Design Techniques \\ Iraq
}

\begin{abstract}
Digital publications possess the elements of uniqueness in the implementation because they are a technical treatment according to the various design programs that formed the basis element in highlighting them and giving them properties that may be the elements that emphasize the objective for which these forms were used in the publications and the different ones.

Magazine covers include advertisements for fashion that carry different meanings and contents depending on what the meanings of the meanings that appear in that declaration, and therefore the research came to highlight the inherent in the designs of advertising costumes contained in magazine covers, the research consisted of three chapters, The problem of research that was asked by the following question: What is embodied in fashion designs Advertising digitally printed? The second chapter is represented by the theoretical framework which was based on the theoretical aspect that strengthens the research and touches on its subject. The third chapter deals with the research procedures and its results. The research was enhanced by drawing on the resources that covered the research topics, as well as the summary in English.
\end{abstract}




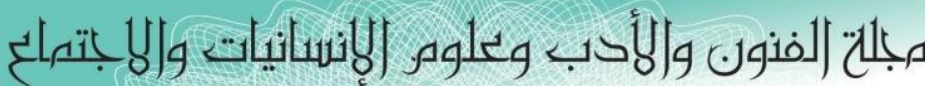

Journal of Arts, Literature, Humanities and Social Sciences

ISSN online: 2414 - 3383

ISSN print: 2616 - 3810

\section{العدد (43) ايلول - سبتمبر 2019}

مشكلة البحث : تتضمن اغلفة المجلات تتعدد للوسائل التصميمية والتنفيذية ولكل وسيلة صفات

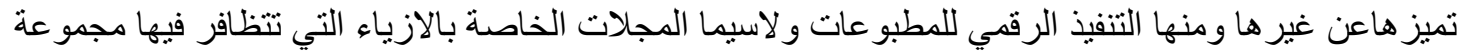

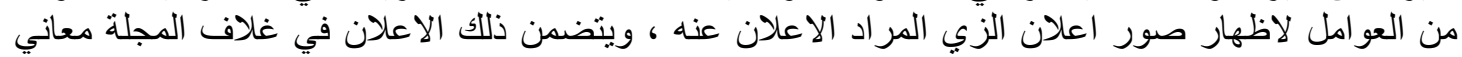

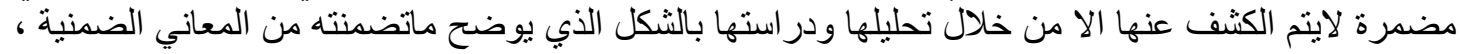

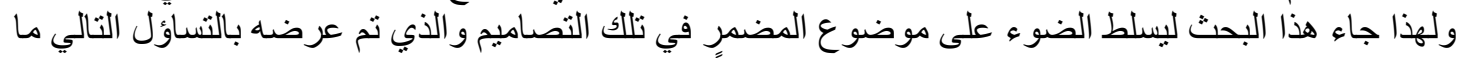
هو المضمر في تصاميم الازياء الاعلانية المطبوعة رلاء رقمياً؟

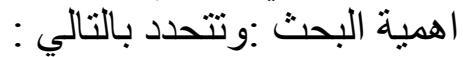

1- سيسهم في التعرف على على آلمعاني المضمرة في تصاميم الازياءالمصورة ضمن اعلانات اغلفة المجلات

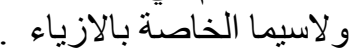

2- سيسلط الضوء على اللى العلاقة بين صورة تصميم الزي وعلاقتها بالعناصر التصميمية التي تشكل الهيكل

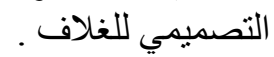

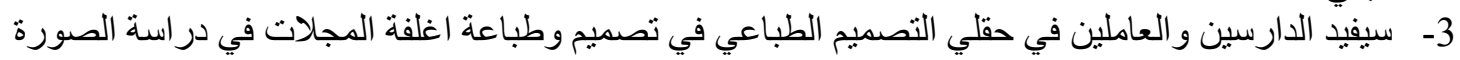

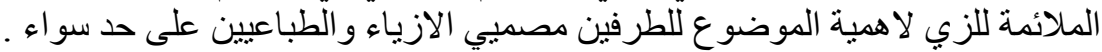

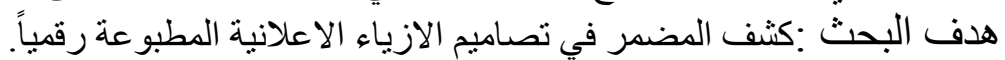

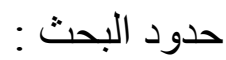

الحد المكاني : اغلفة مجلة فوغ البح العربية .

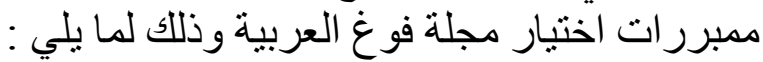

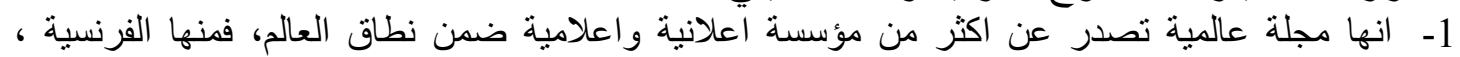

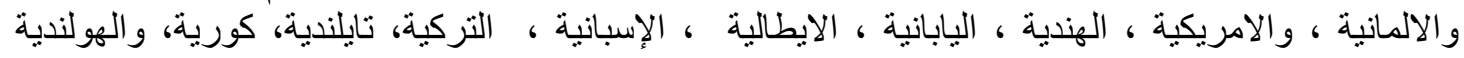

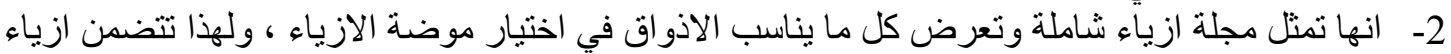

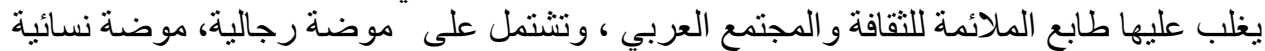

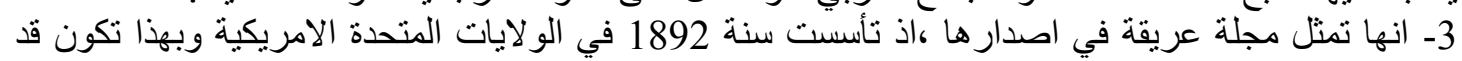

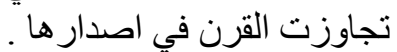

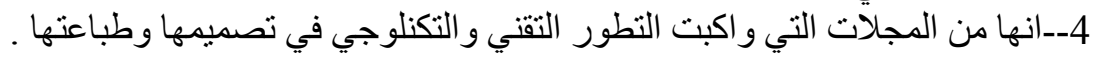

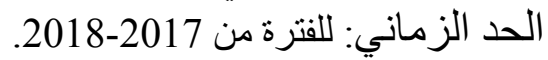
الحد الموضوعي: المضمر في تصاميم الازياء الاعلانية (المصورة على غلاف المجلة ) .

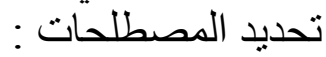

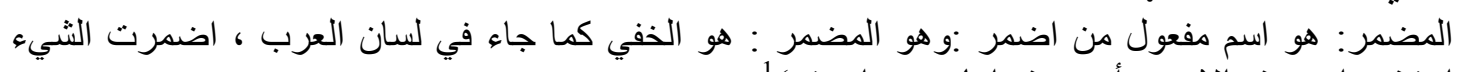

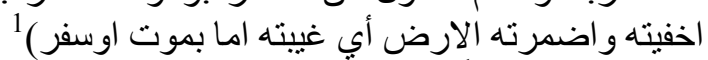

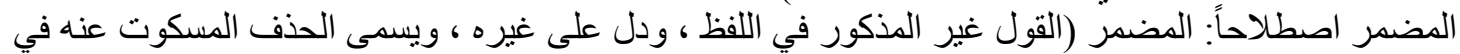

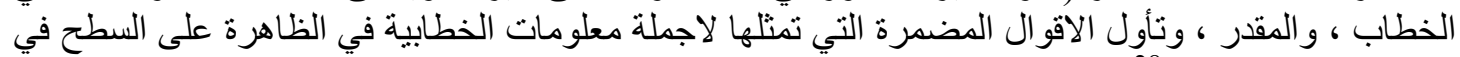

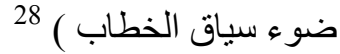
تعرفه الباحثة سهام محسن : بما يتلائم وسياق البحث: بأنه كل المضامين غير الظاهرة في المنجز المطبوع التي

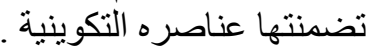

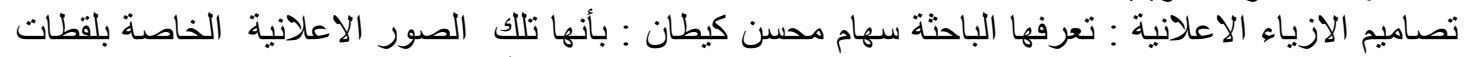

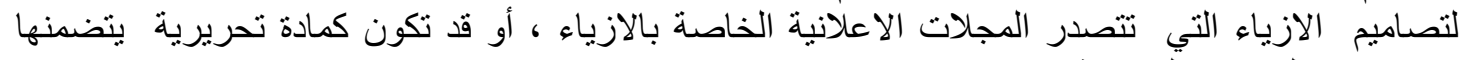

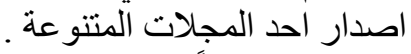
المطبوعة رقمياً : وهي تللك المجلات المبات التي خضعت لمعالجة رقميا سواء في التصميم او الطباعة ولاسيما

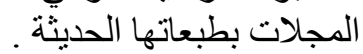




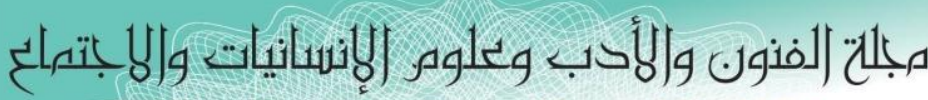
Journal of Arts, Literature, Humanities and Social Sciences

ISSN online: 2414 - 3383

ISSN print: 2616 - 3810

\section{العدد (43) أيلول - لسبتمبر 2019}

تمنلك مفردة المضمر أهمية في اللغة العربية شأنها شأن المفردات التي تتضمنها التها اللغة العية العربية التي تتميز

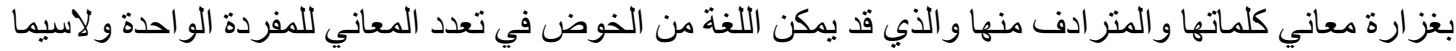

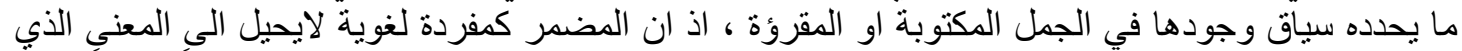

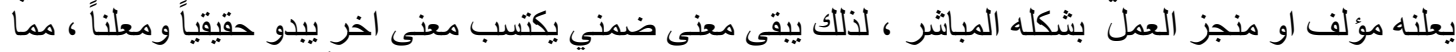

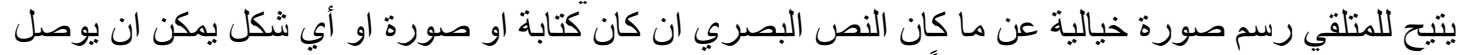

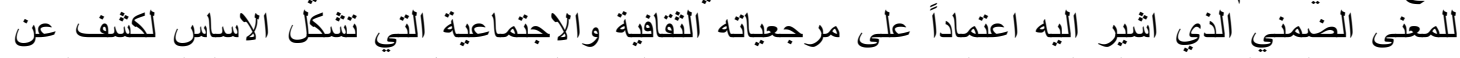

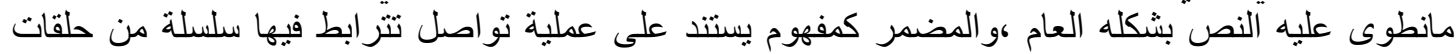

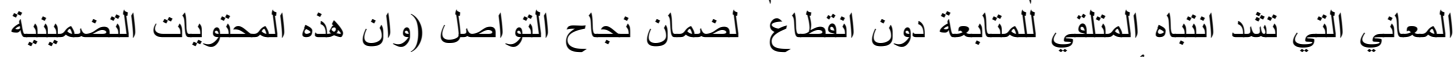

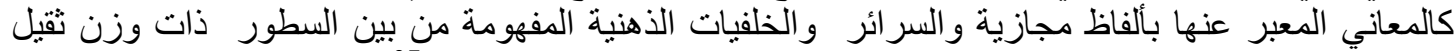

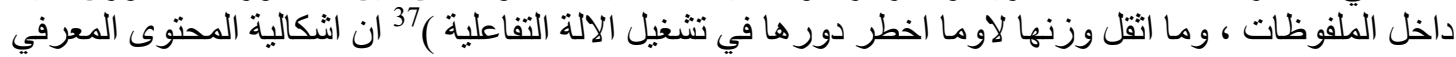

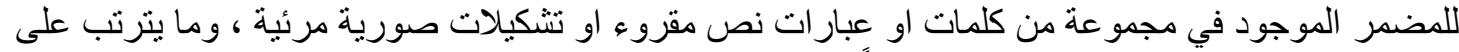

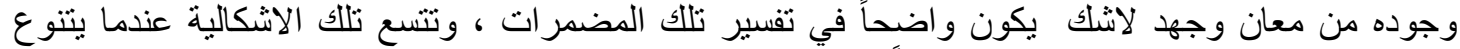

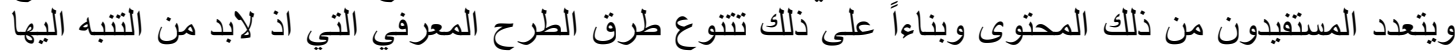

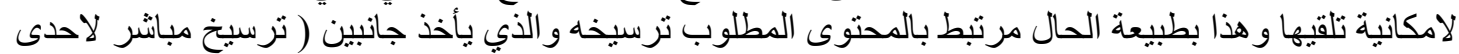

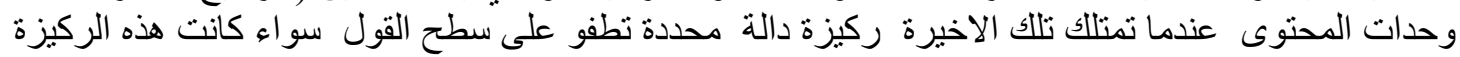

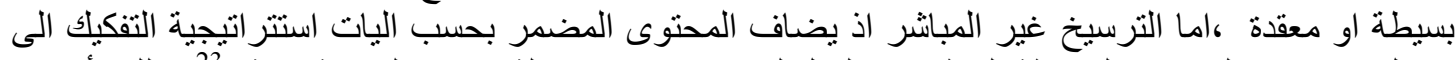

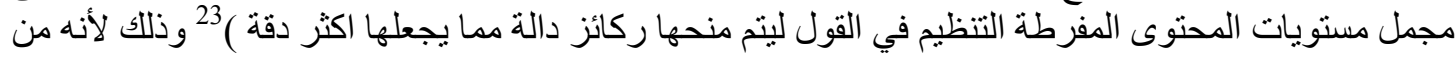

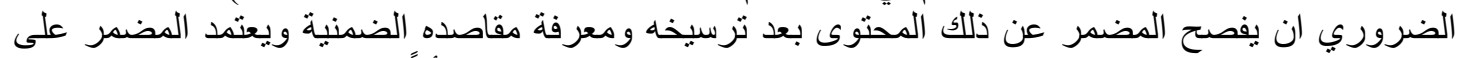

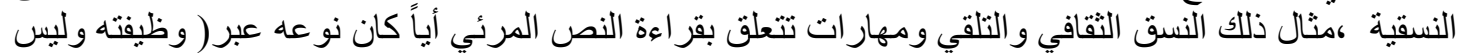

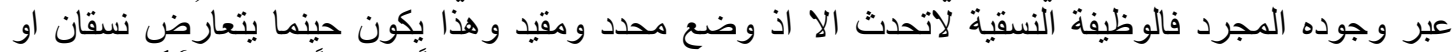

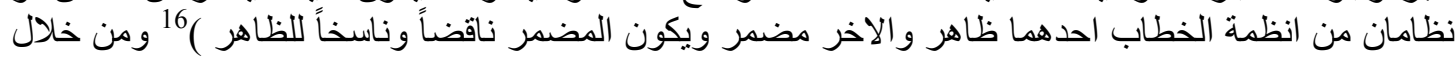

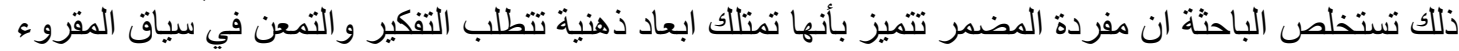

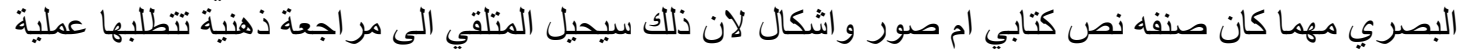

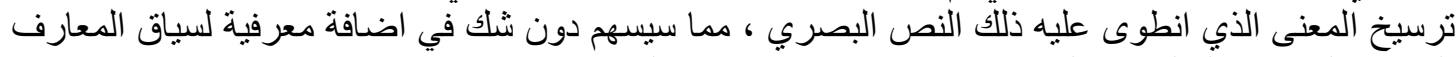

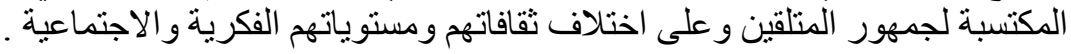

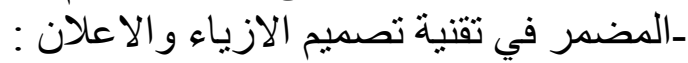

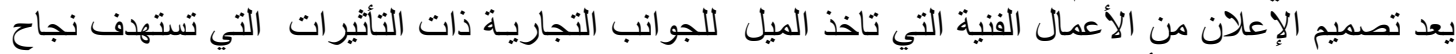

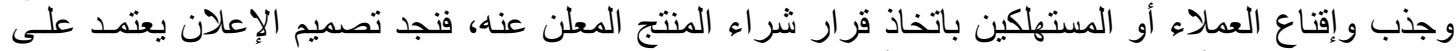

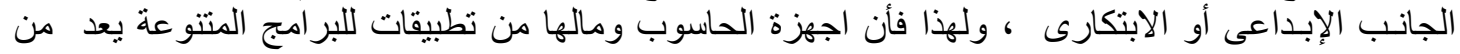

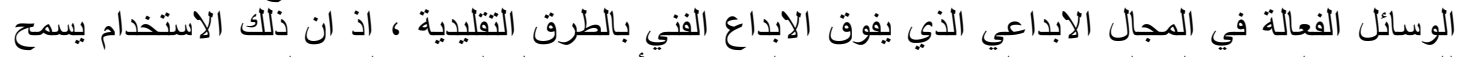

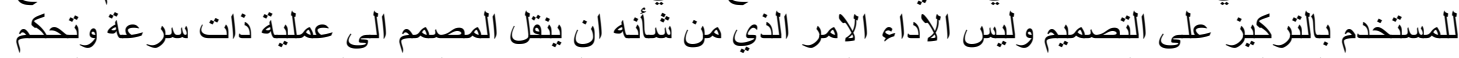

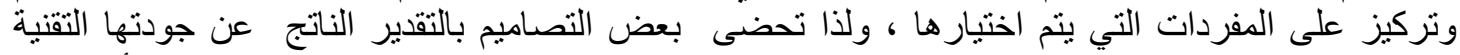

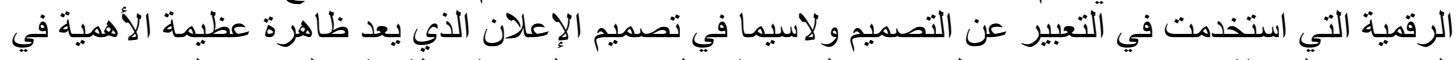

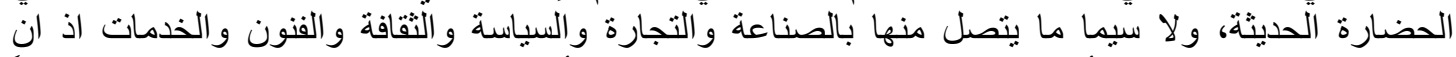

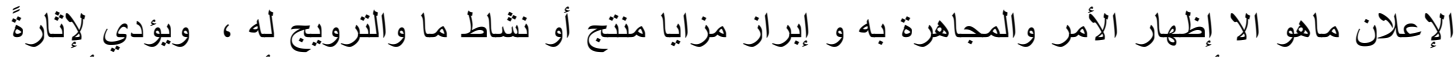

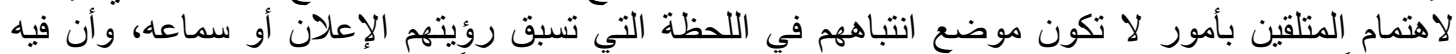

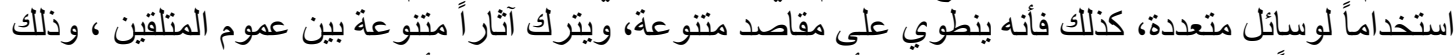

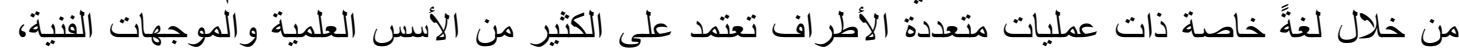

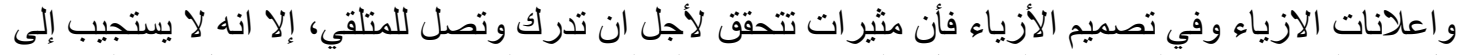

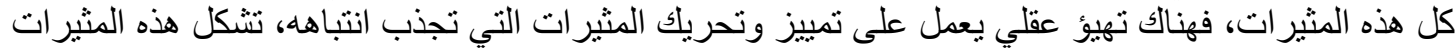




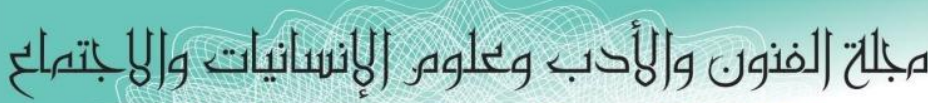
Journal of Arts, Literature, Humanities and Social Sciences

ISSN online: 2414 - 3383

ISSN print: 2616 - 3810

أيلول - لسبتهبر 2019

العدد (43)

ثو ابت يضعها المصمم في تصميم الزي تتطابق مع إدر الك المتلقي لها اذ ان الإدر الك لا بعني (تطابق الخاصية

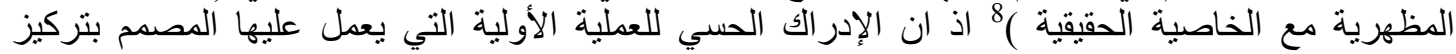

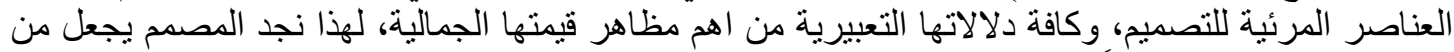

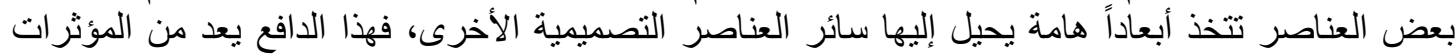

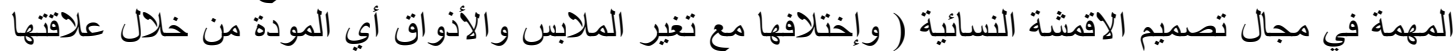

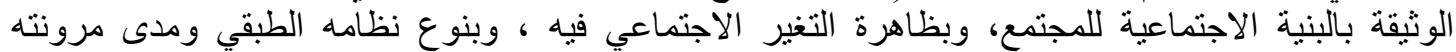

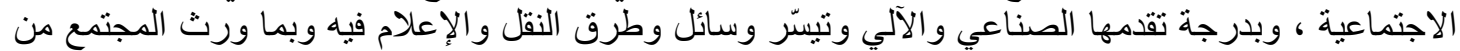

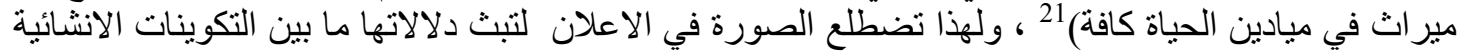

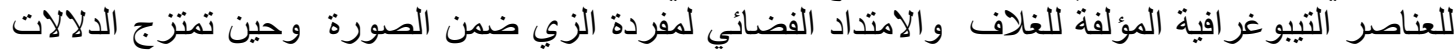

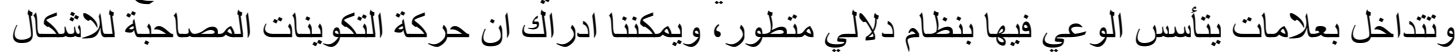

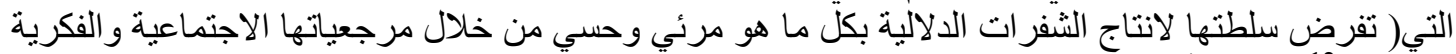

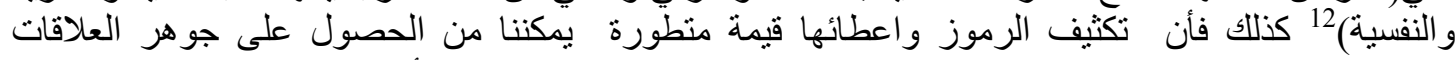

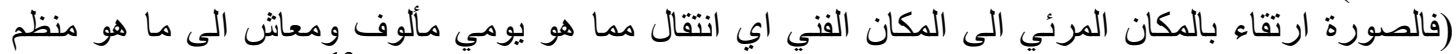

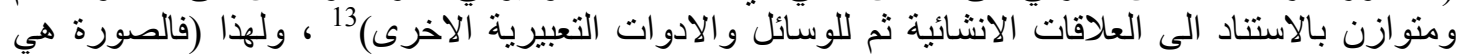

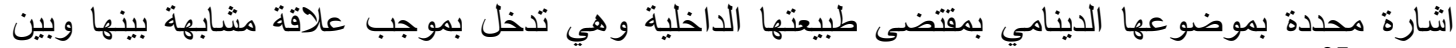

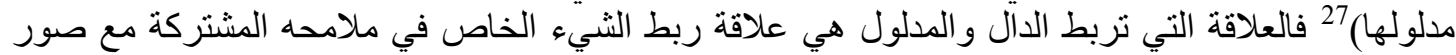

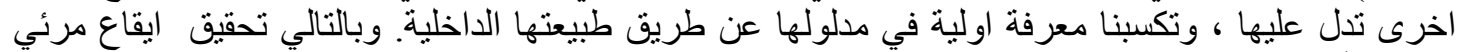

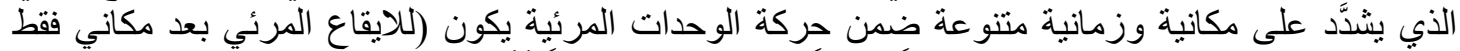

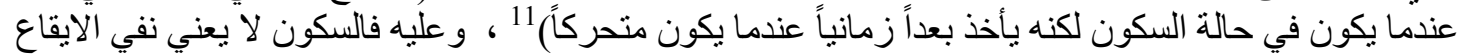

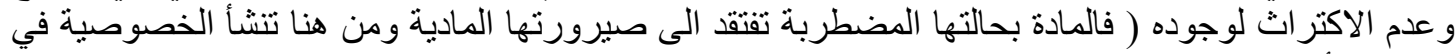

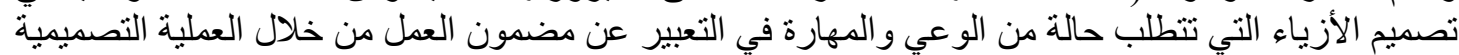

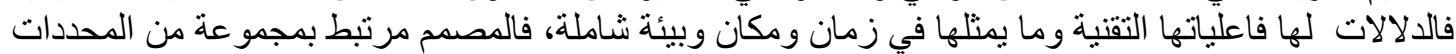

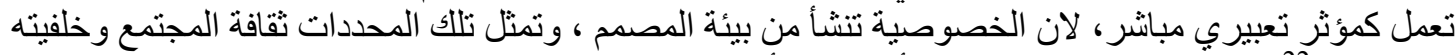

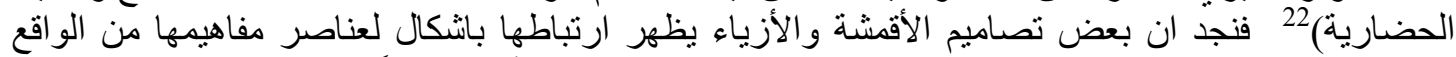

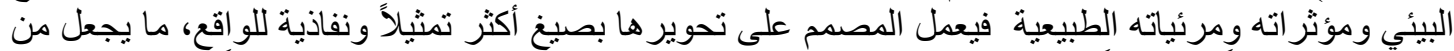

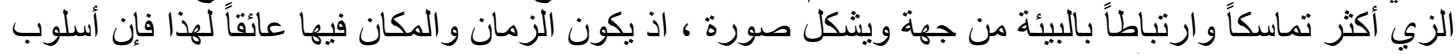

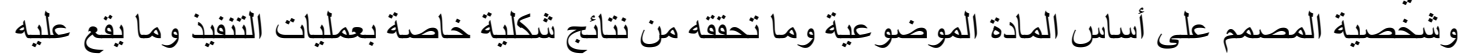
من مؤثرات و استجابات باختلاف الذائقة يتطلب من المصدم و المتلقي أبعادا عقلية معرفية، جمالية واجتية والتماعية

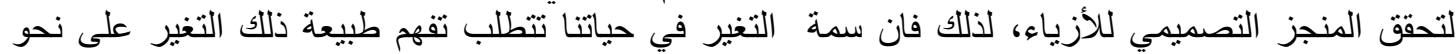

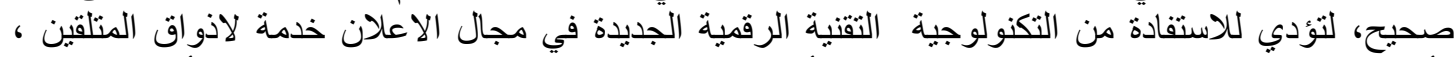

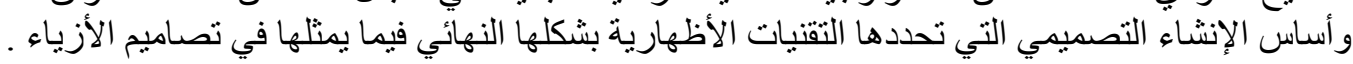

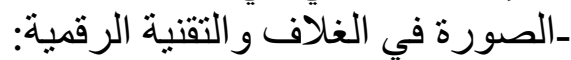

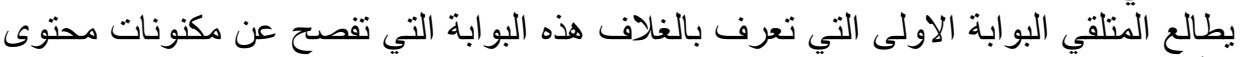

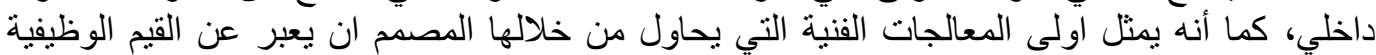

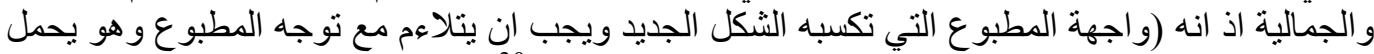

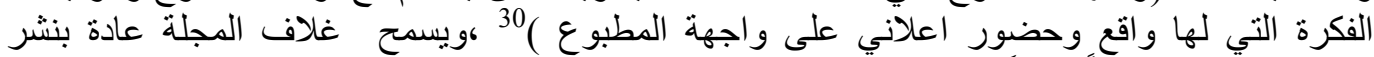

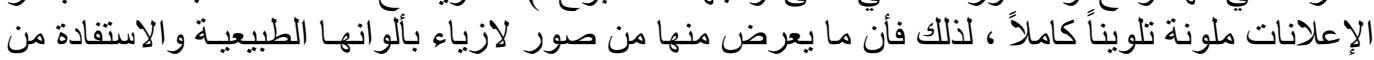

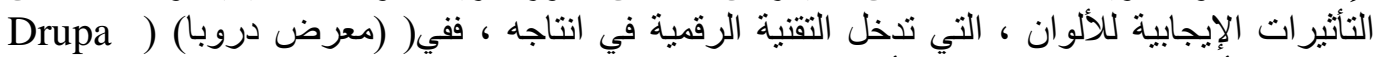

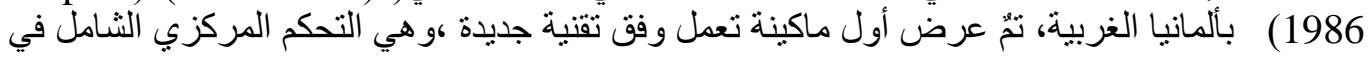

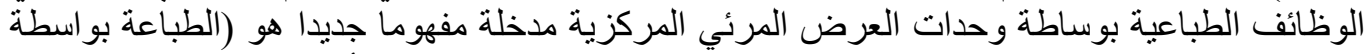

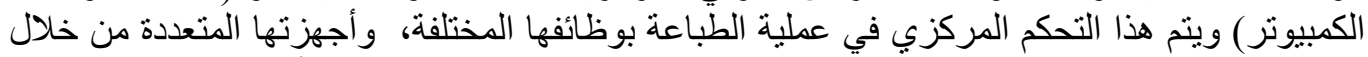

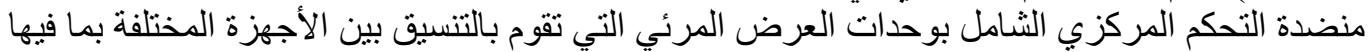

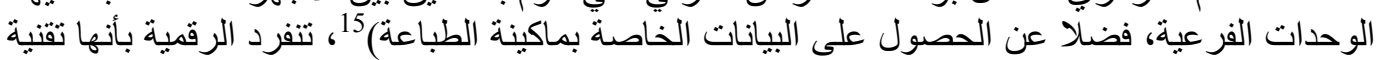




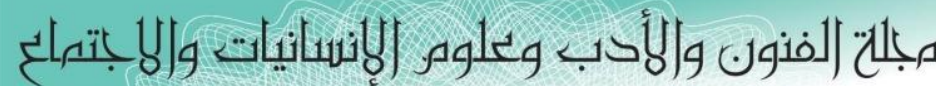
Journal of Arts, Literature, Humanities and Social Sciences

ISSN online: 2414 - 3383

ISSN print: 2616 - 3810

\section{العدد (43) أيلول - سبتمبر 2019}

تكويد الاعلام بو اسطة الحاسوب ، و تسمح اما بنقل فلم على شريط او تصويره مباشرة بواسطة (كاميرات

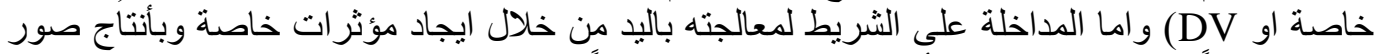

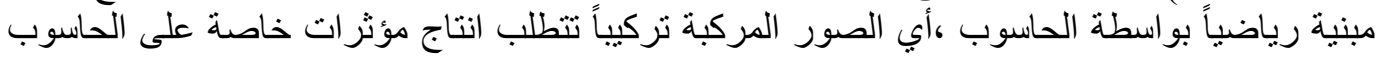

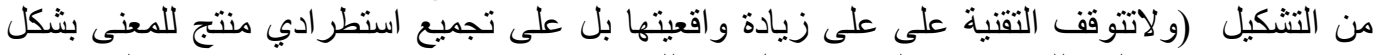

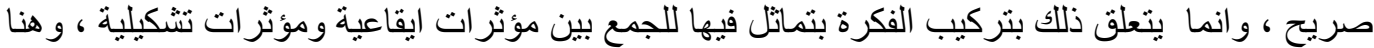

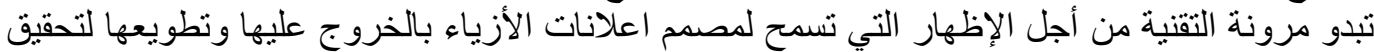

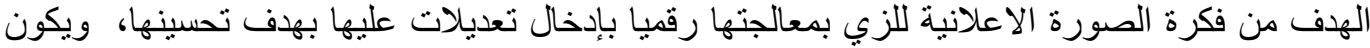

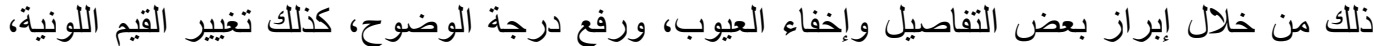

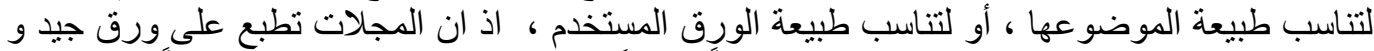

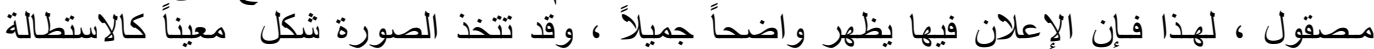

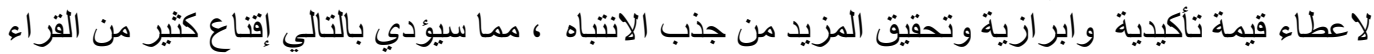

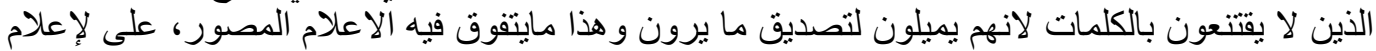

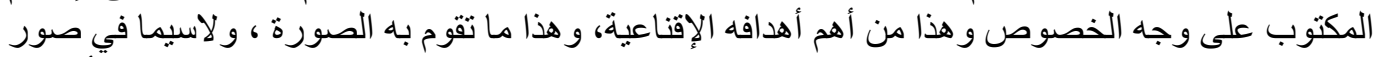

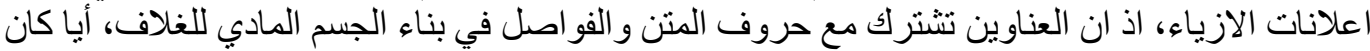

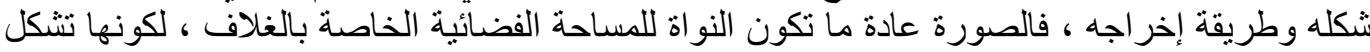

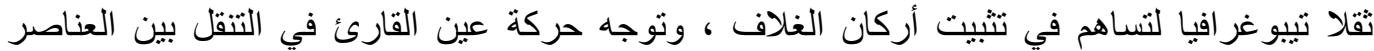

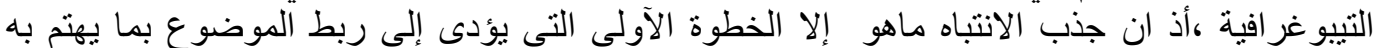

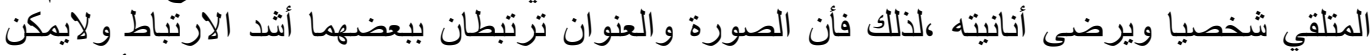

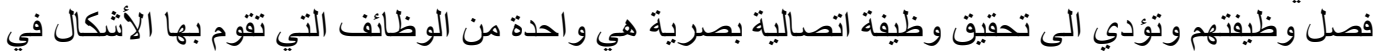

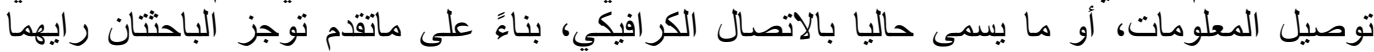

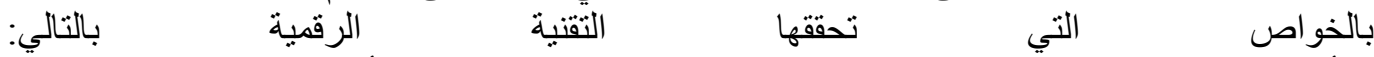
1-أن تضيف التقنية عنصر ا من عناصر الإمتاع البصري حيث يجب تكون أن تنتوفر فيها اللمسة الفنية.

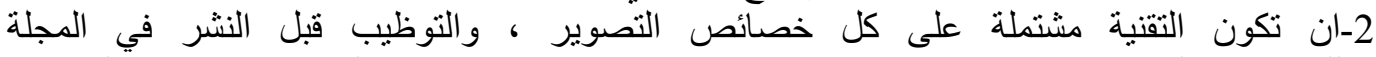

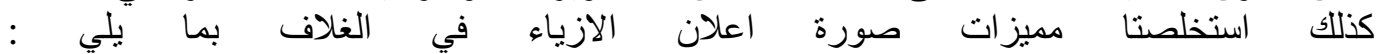

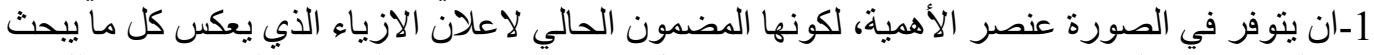

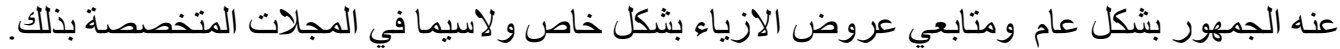

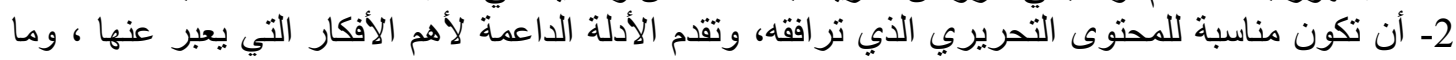

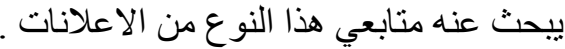

المبحث الثناني :الهضمر و عمليات التأويل في الاعلانات الرقمية :

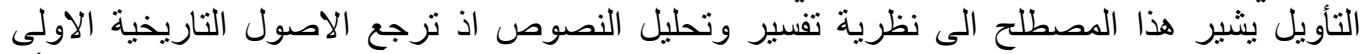

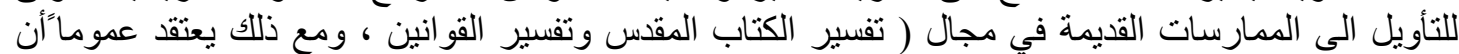

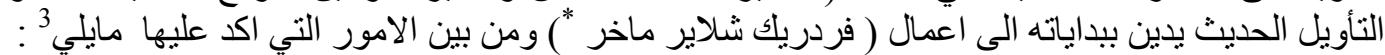

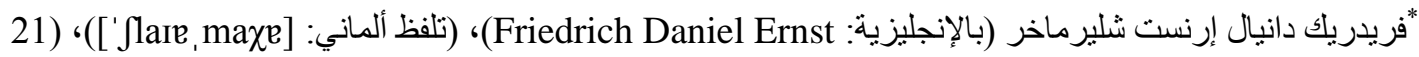
نوفمبر 1768 - 12 فبر اير 1834) كان لاهوتي وفيلسوفو عالم الكتاب المقدس، عرف عنه محاولته التوفيق بين الانتقادات

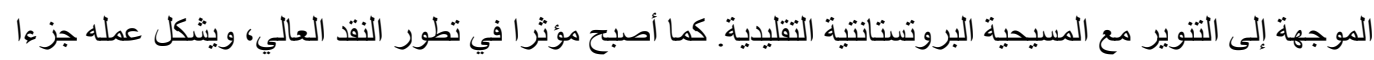

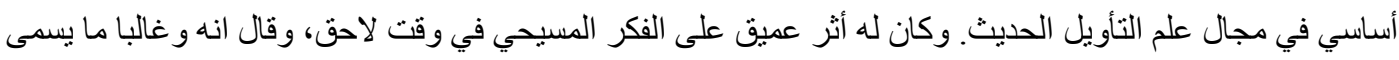

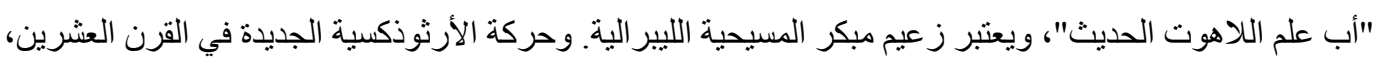

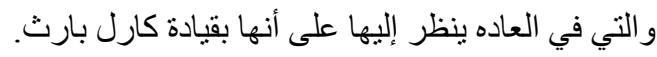




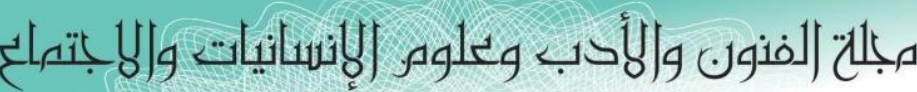

Journal of Arts, Literature, Humanities and Social Sciences

ISSN online: 2414 - 3383

ISSN print: 2616 - 3810

\section{العدد (43) أيلول - لسبتمبر 2019}

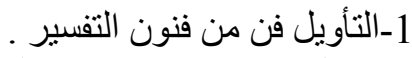

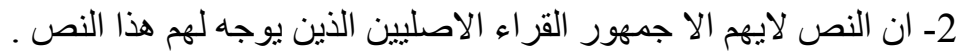

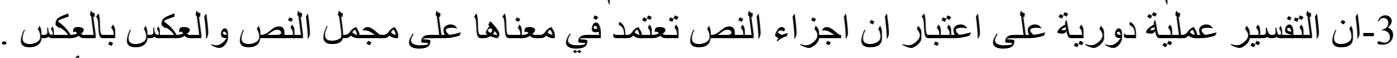

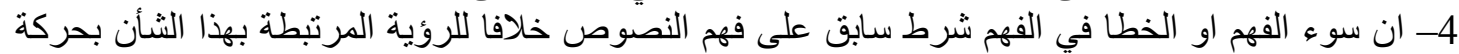

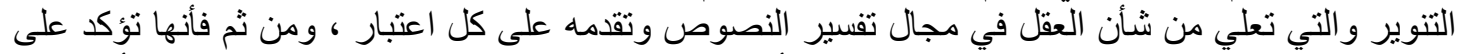

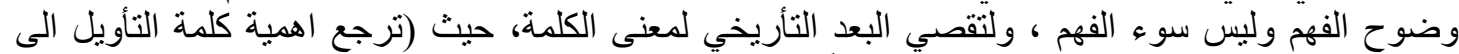

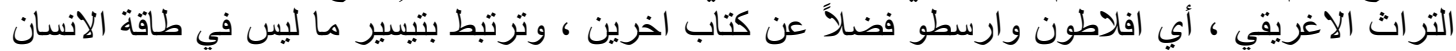

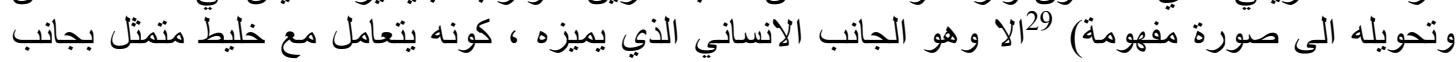

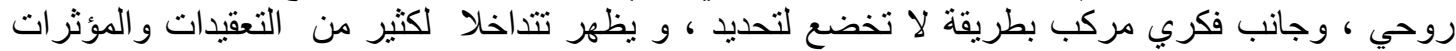

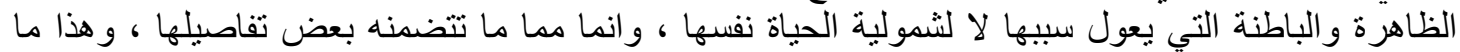

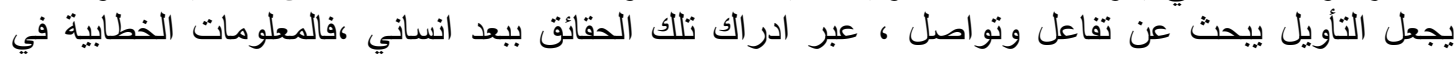

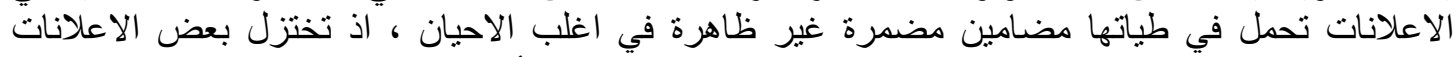

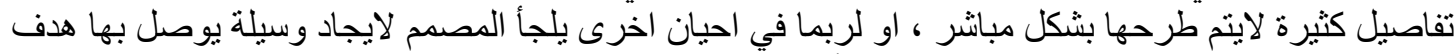

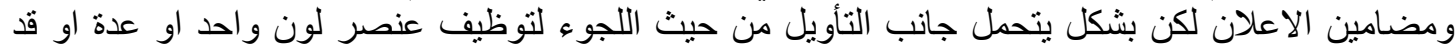

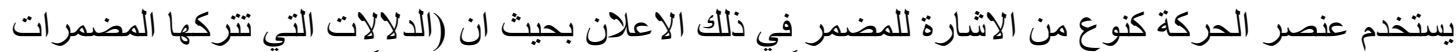

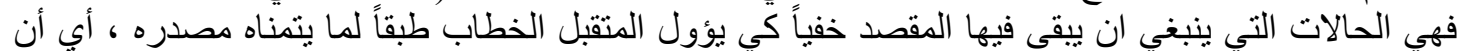

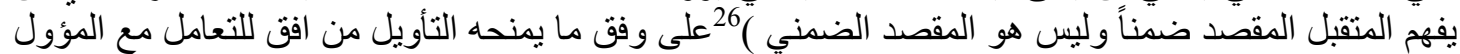

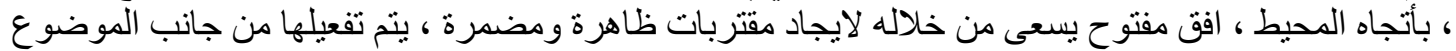

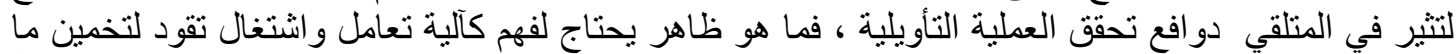

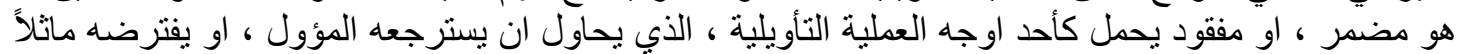

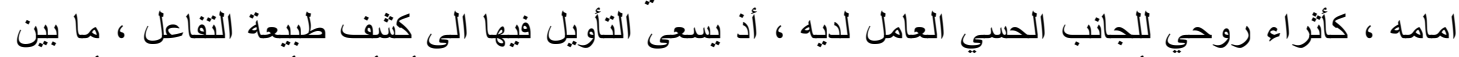

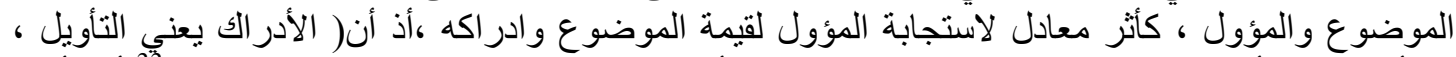

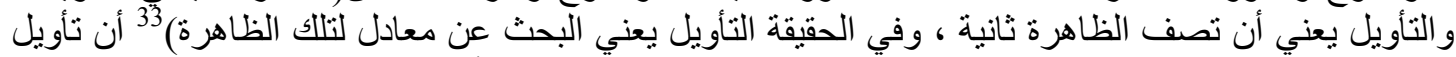

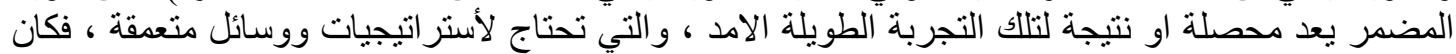

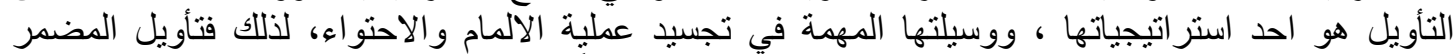

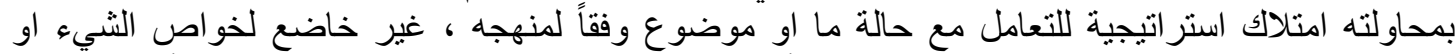

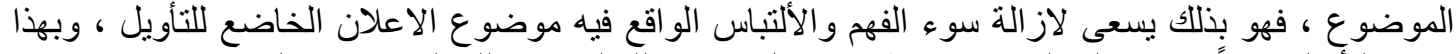

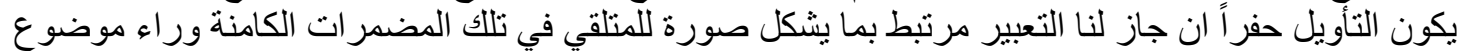

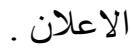

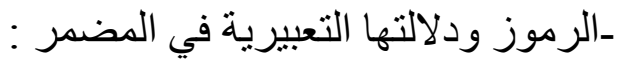

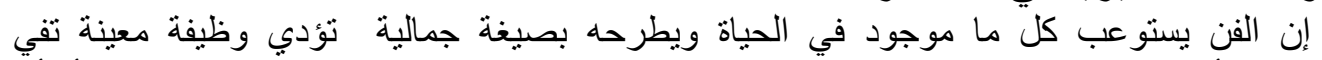

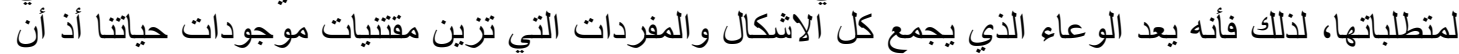

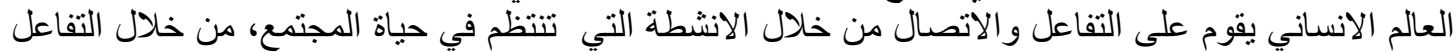

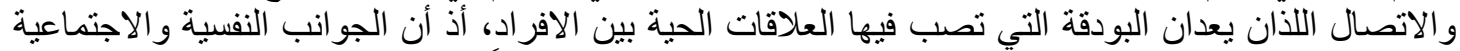

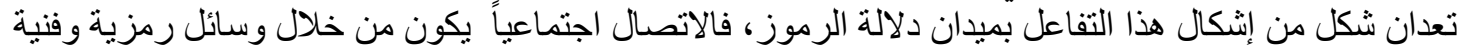

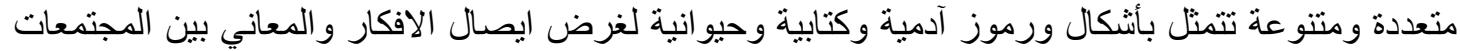

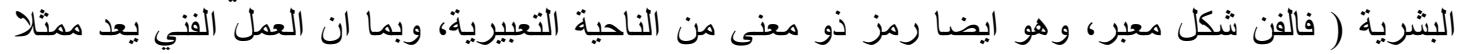

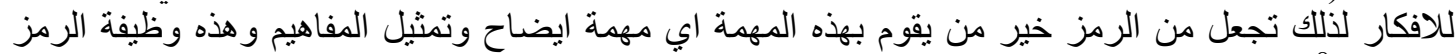

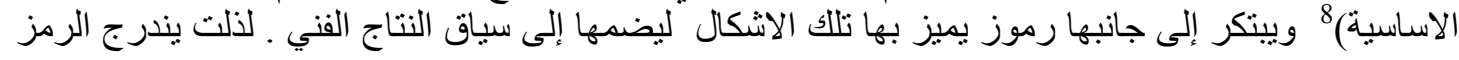

https://ar.wikipedia.org/wiki/\%D9\%81\%D8\%B1\%D9\%8A\%D8\%AF\%D8\%B1\%D9\%8A\%D 9\%83_\%D8\%B4\%D9\%84\%D9\%8A\%D8\%B1\%D9\%85\%D8\%A7\%D8\%AE\%D8\%B1 


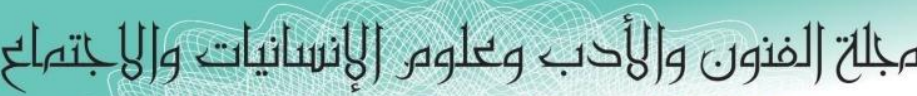

Journal of Arts, Literature, Humanities and Social Sciences

ISSN online: 2414 - 3383

ISSN print: 2616 - 3810

\section{العدد (43) أيلول - سبتمبر 2019}

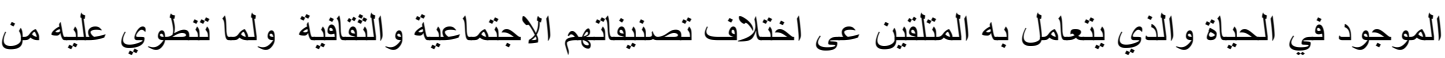

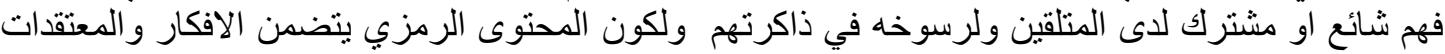

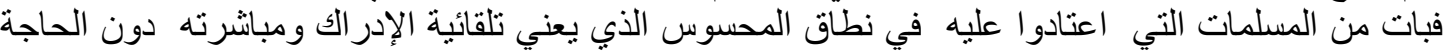

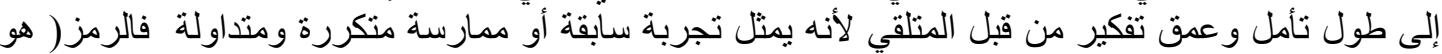

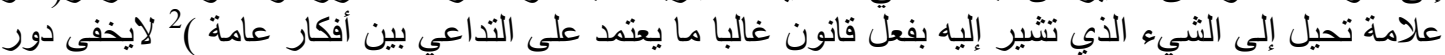

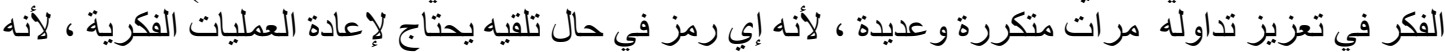

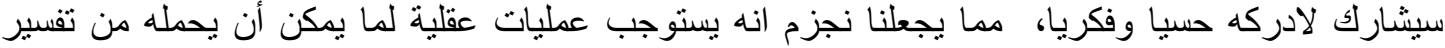

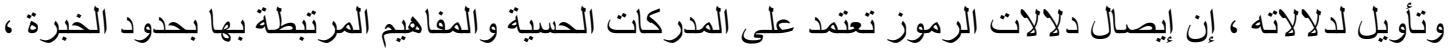

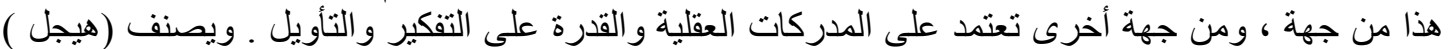

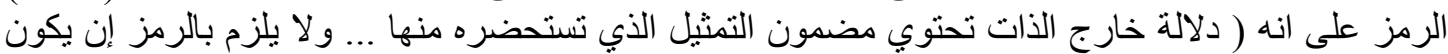

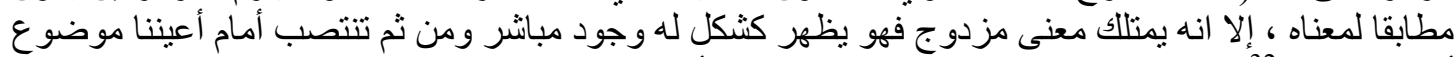

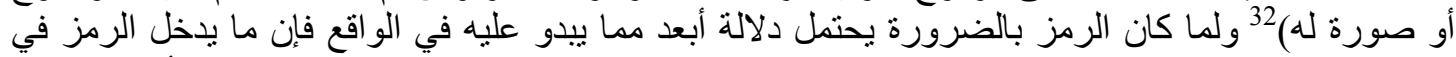

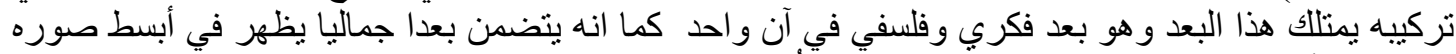

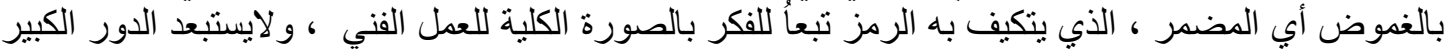

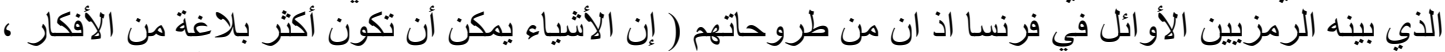

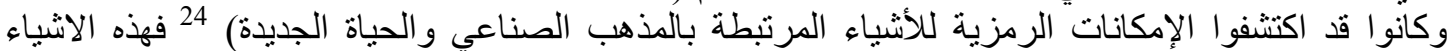

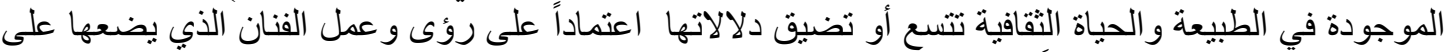

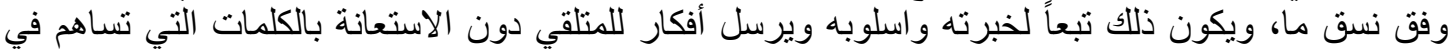

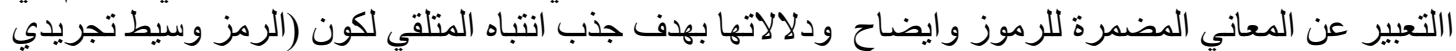

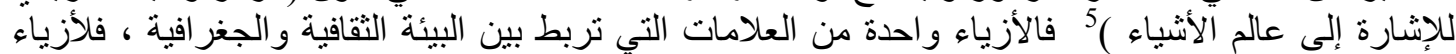

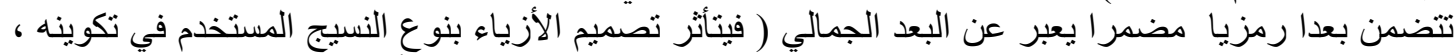

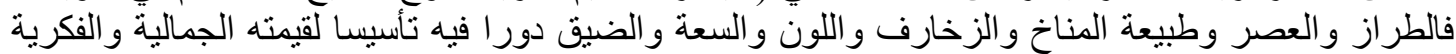

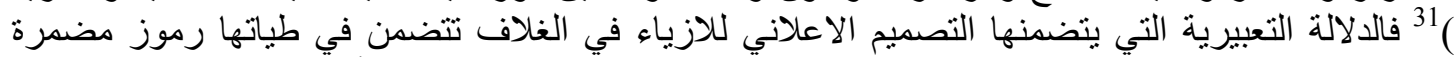

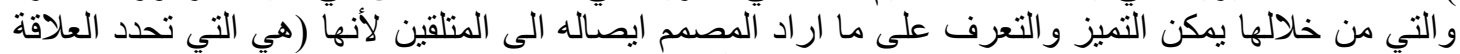

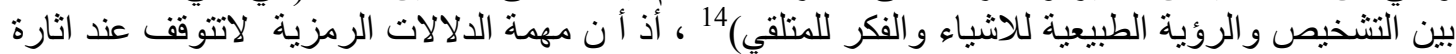

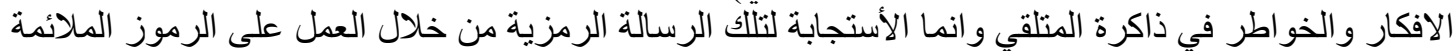

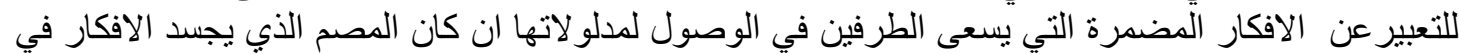

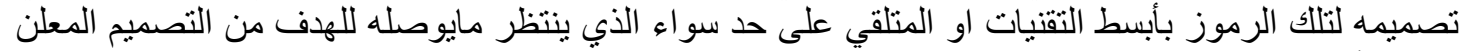

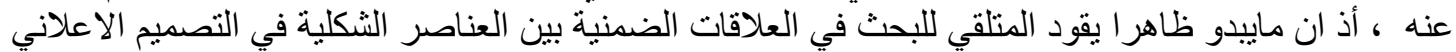

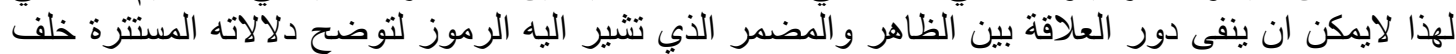

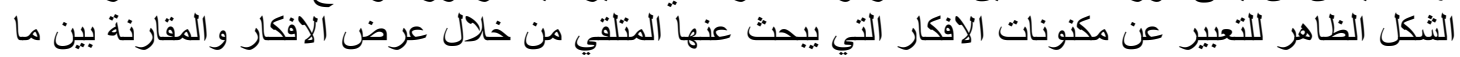

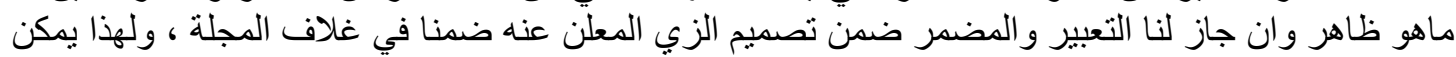

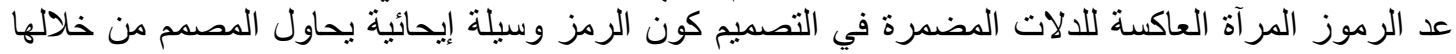

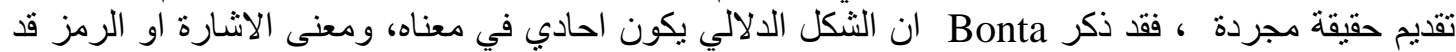

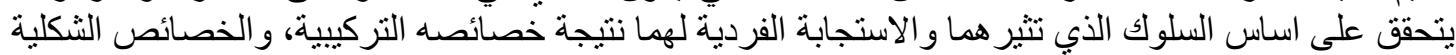

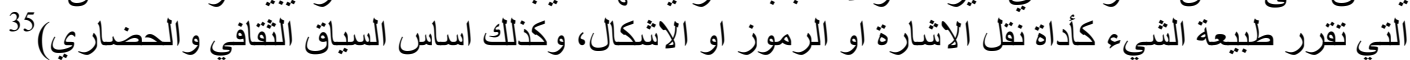

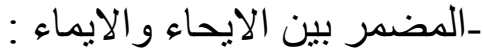

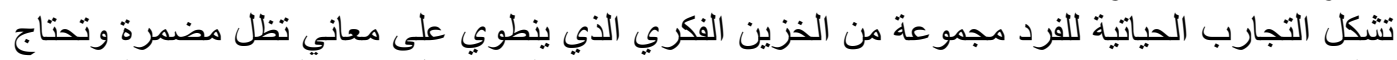

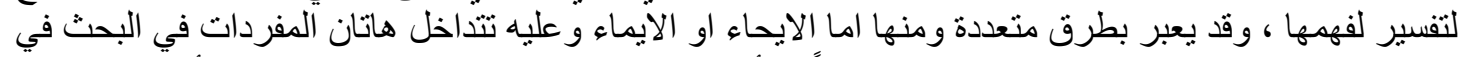

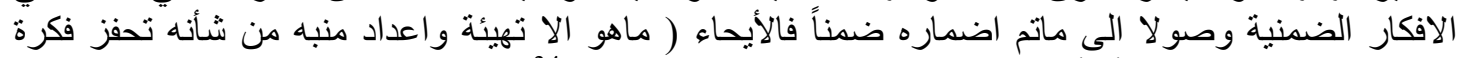

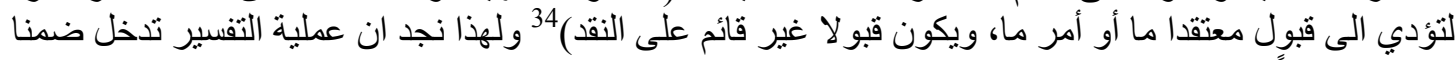

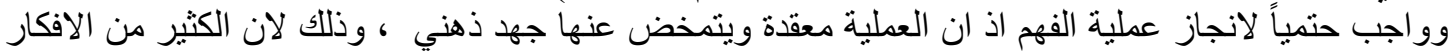

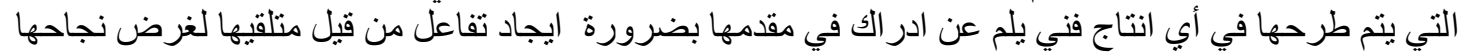




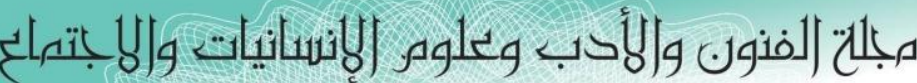
Journal of Arts, Literature, Humanities and Social Sciences

ISSN online: 2414 - 3383

ISSN print: 2616 - 3810

\section{أيلول - لسبتهبر 2019}

العدد (43)

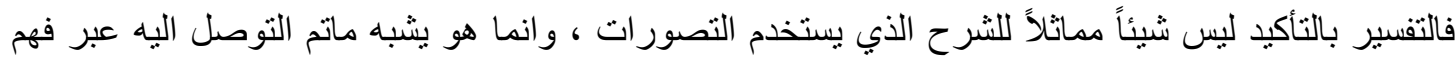

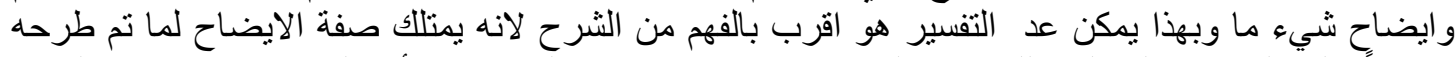

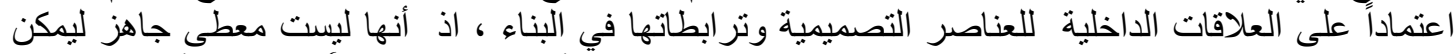

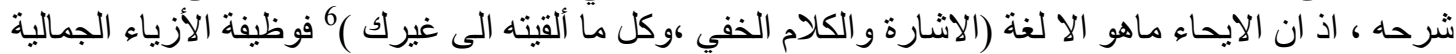

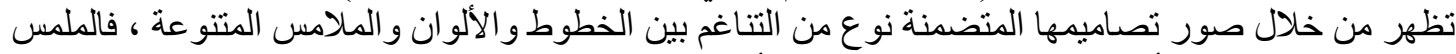

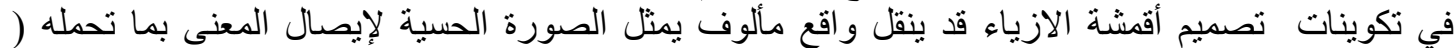

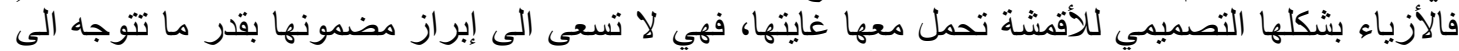

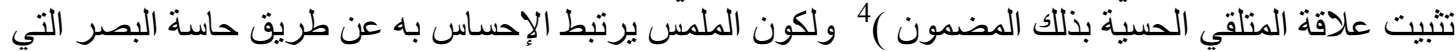

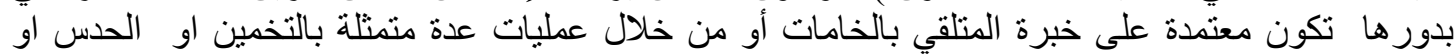

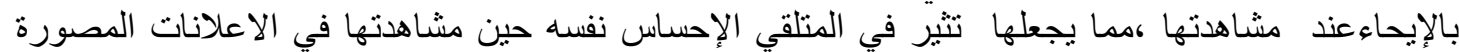

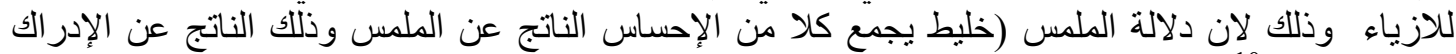

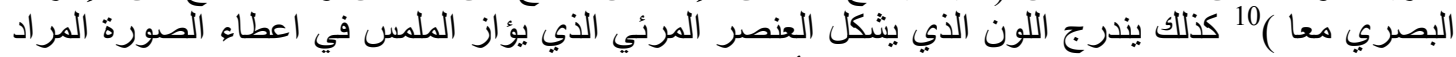

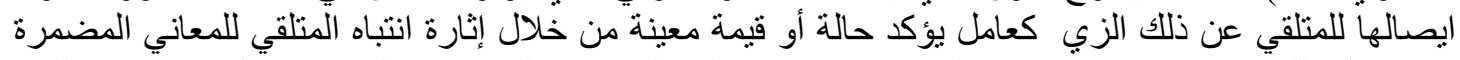

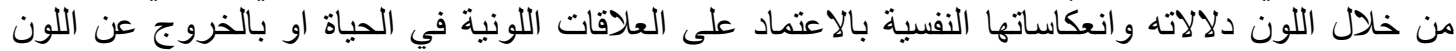

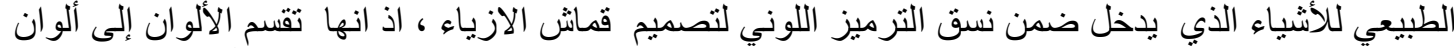

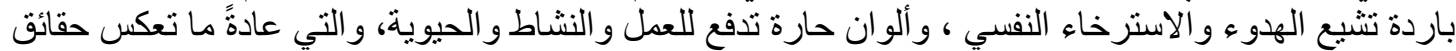

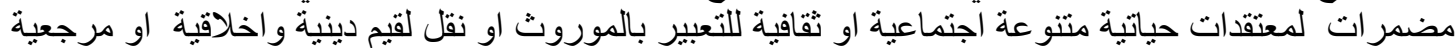

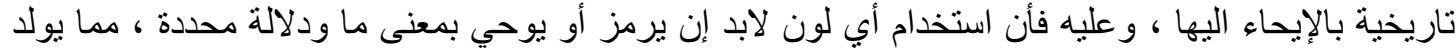

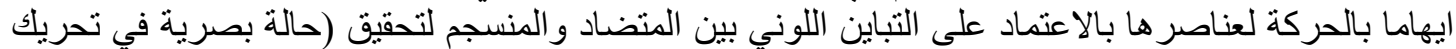

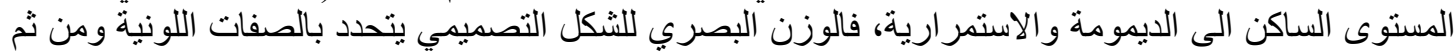

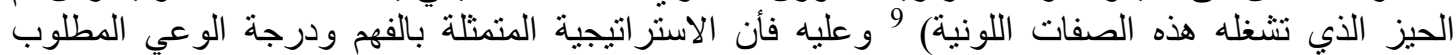

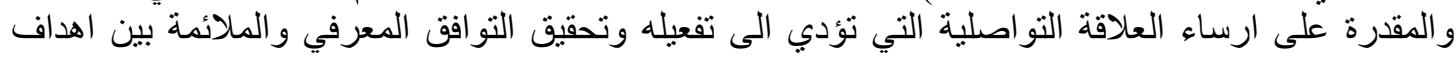

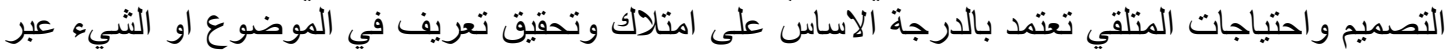

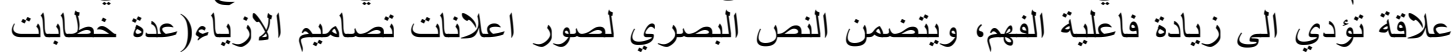

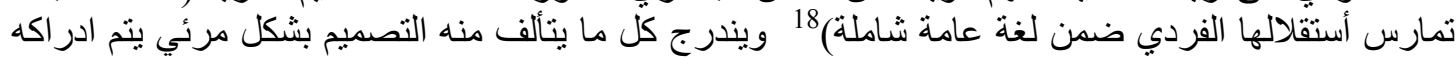

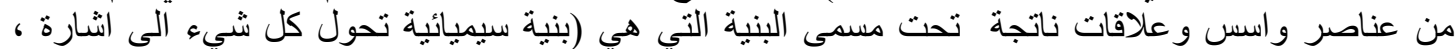

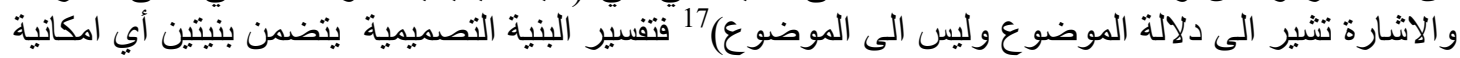

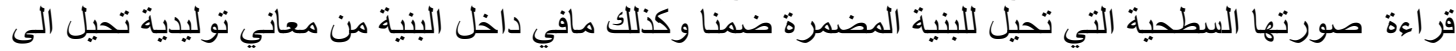

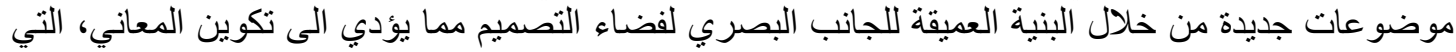

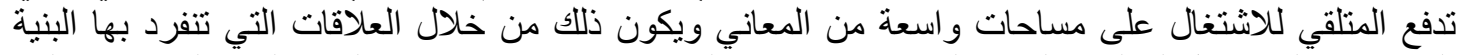

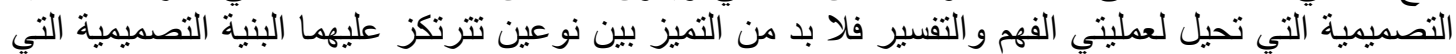

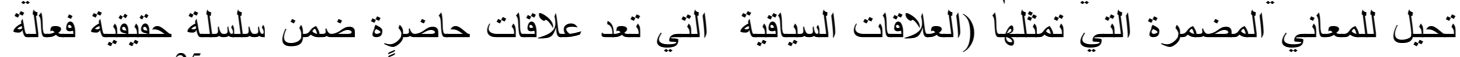

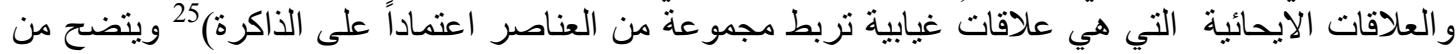

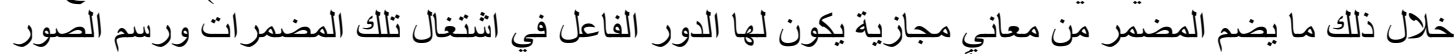

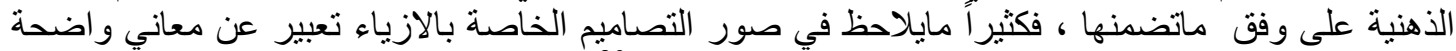

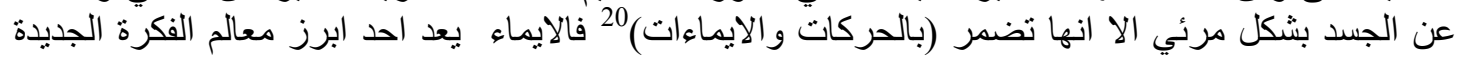

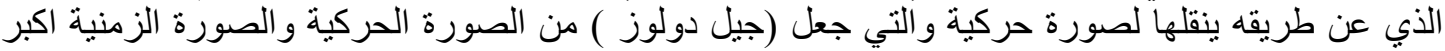

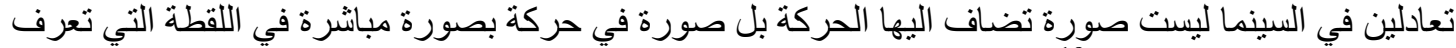

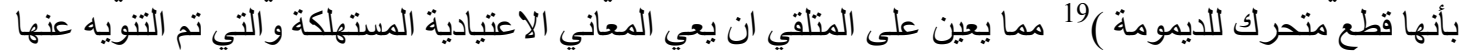

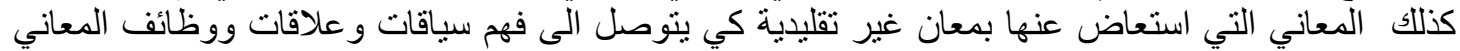

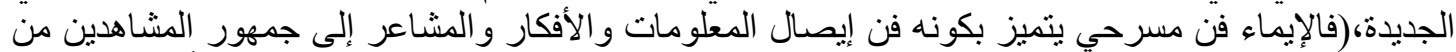

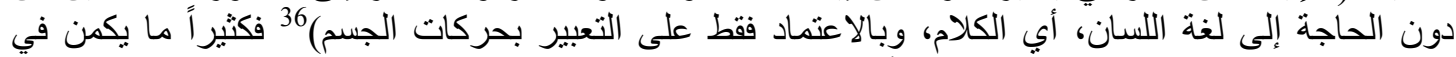
الايماء قدرة على انشاء موقف ذو دلالة ما ، أنشارة للجسد وحركاته و عليه يمكننا تمييز نو عين من الإيماءات، هما: 


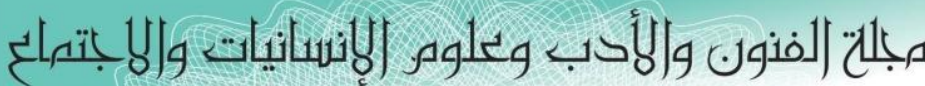

Journal of Arts, Literature, Humanities and Social Sciences

ISSN online: 2414 - 3383

ISSN print: 2616 - 3810

\section{العدد (43) أيلول - سبتمبر 2019}

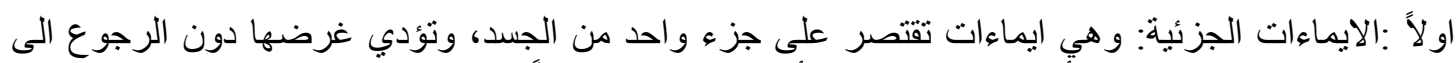

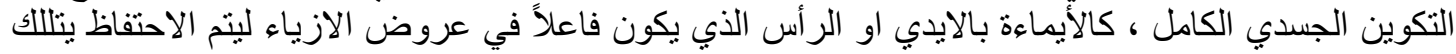

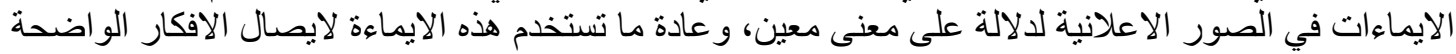

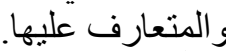

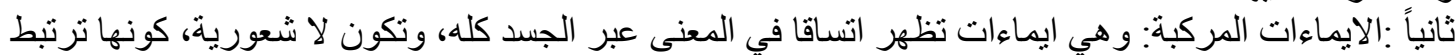

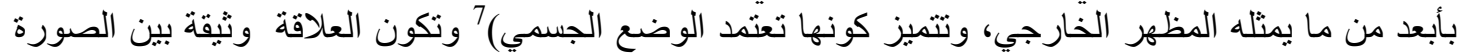

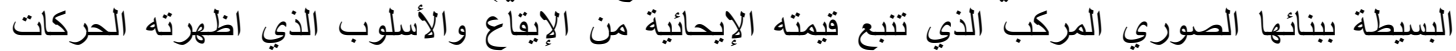

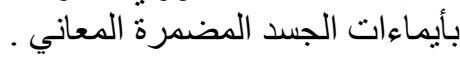

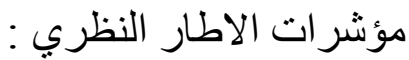

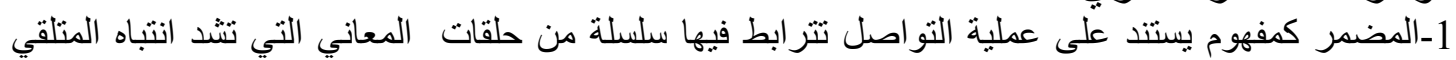

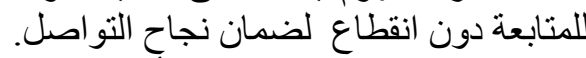

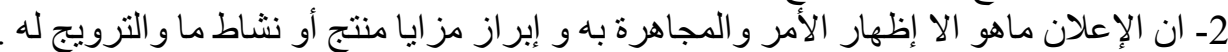

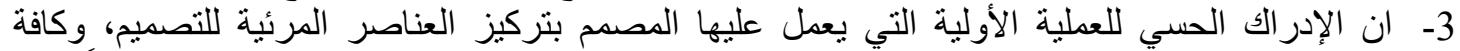

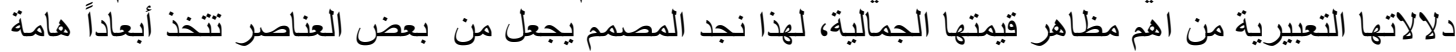

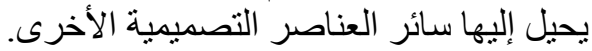
4- يرتبط المصمم بمجموعة من المحددات التي تعمل كمؤثر تعبيري مباشر، لان الخصوص الخصوصية تنشأ من بيئة

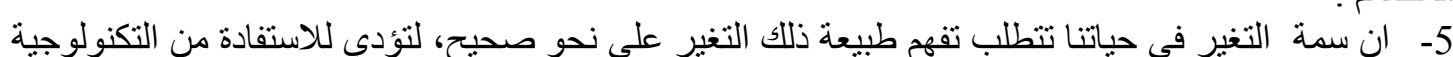

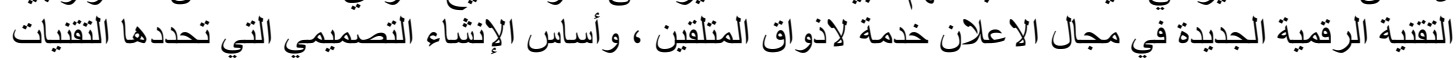

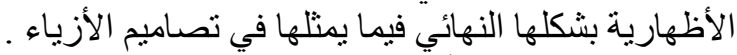

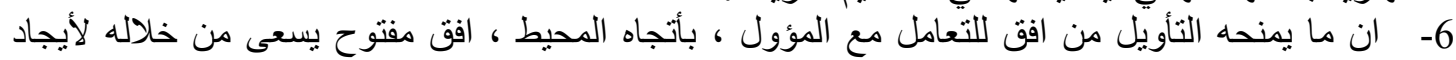

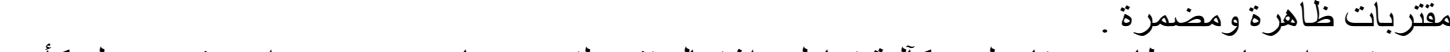
7- يتبين ان ما هو ظاهر يحتاج لفهم كآلية تعامل واشتخغال تقود لتخمين ما هو مضمر ، او مفقود يحمل كأحد

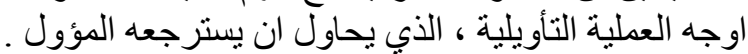

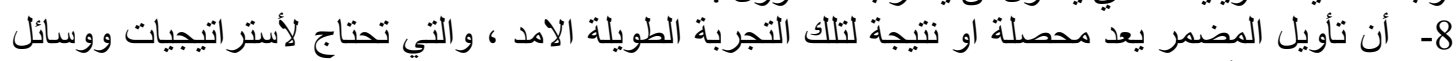

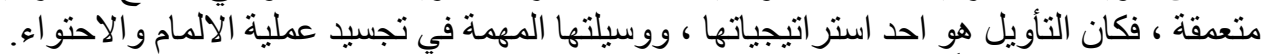

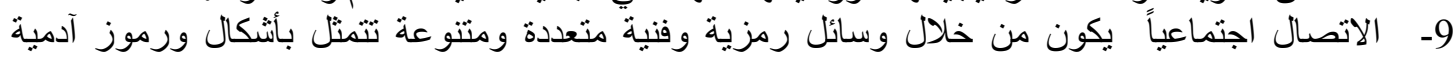

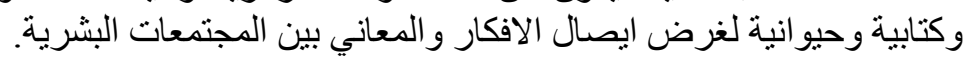

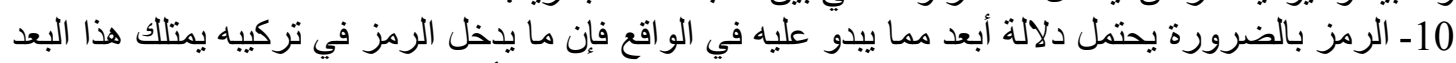

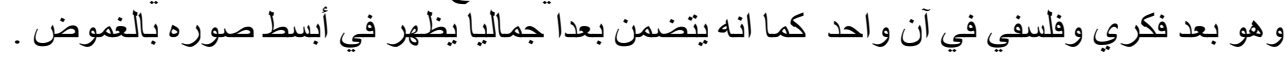

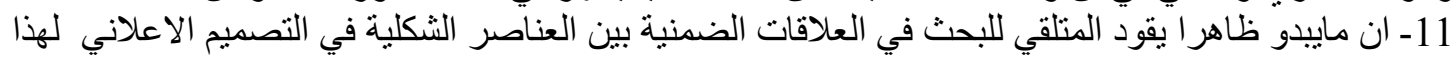

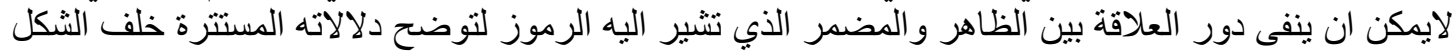

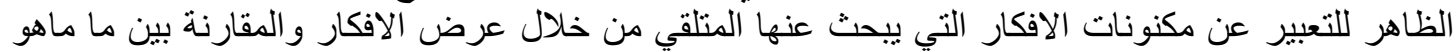

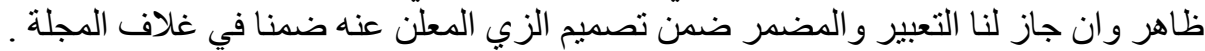

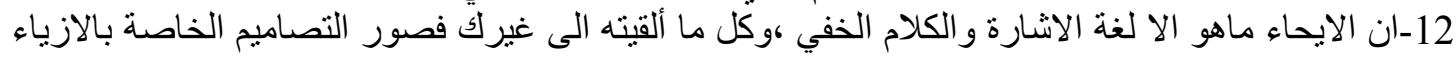

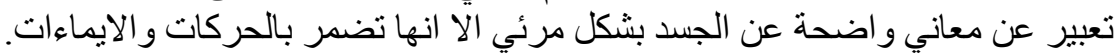

الفصل الثالث : اجراعات البحث ـ منهج البحث: اعتمدت الباحثتان على المنهج الوصن الوصفي في التحليل في العينة كونه الاكثر ملائمة ويتناسب

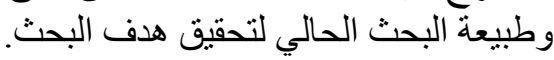
-مجتمع البحث: بعد الاستطلاع والبحث في المصادر العلمية ذات العلاقة بالموضوع نوصلت الباحثنان الى

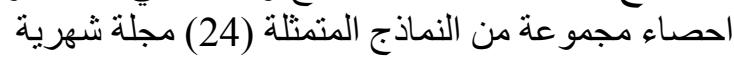




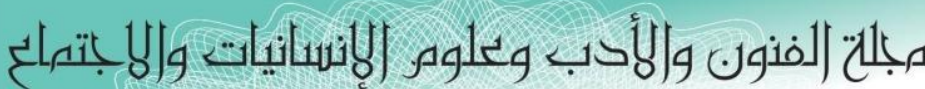

Journal of Arts, Literature, Humanities and Social Sciences

ISSN online: 2414 - 3383

ISSN print: 2616-3810

\section{العدد (43) أيلول - سبتهبر 2019}

ـعينة البحث : تمثلت عينة البحث بأختيار عينة عشوائية من المجتمع أذ بلغ عددها (3) وشكلت نسبة

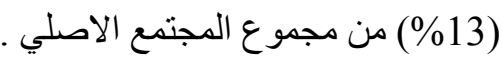
ـاداة البحث : تمثلت اداة البحث في تحليل العينات بالاعتماد على ماسفرت عنه مؤشرات الاطار النظري ،

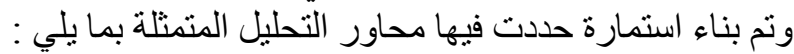

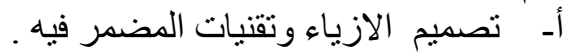

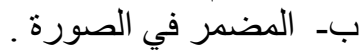

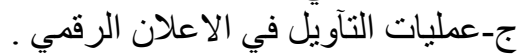

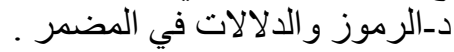

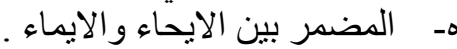

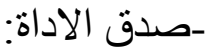

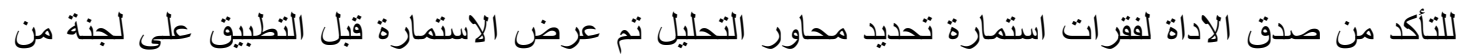

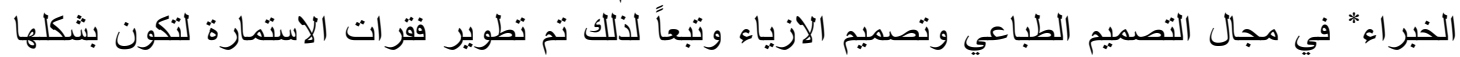

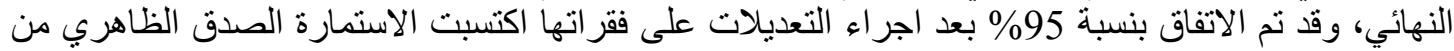

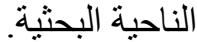

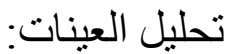

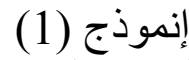
الوصف العام

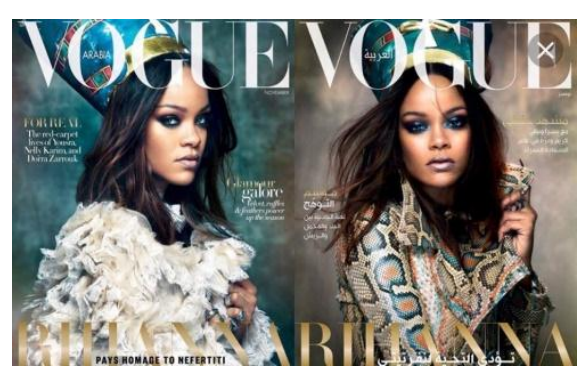

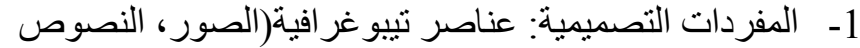
الكتابية، الالوان)، مفردات طبيعية (حيو انية) تمثلت بالثكل الخداصن الخاص بجلد

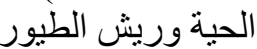

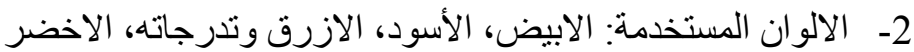

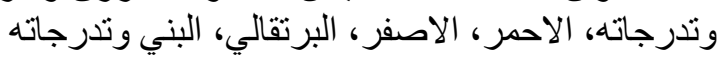
3- الاستخدام الوظيفي: غلاف مجلة الإنية

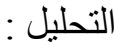

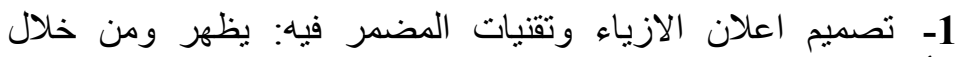

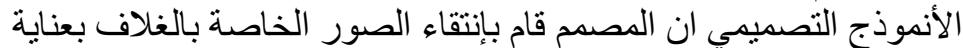

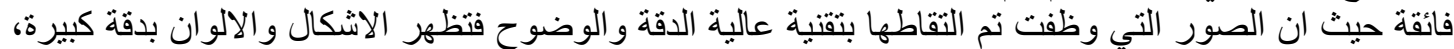

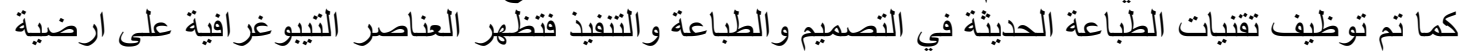

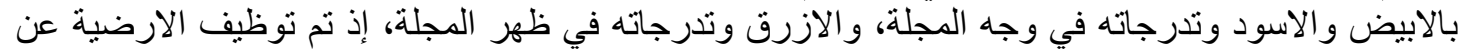

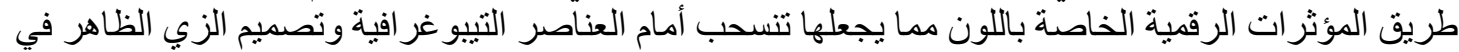

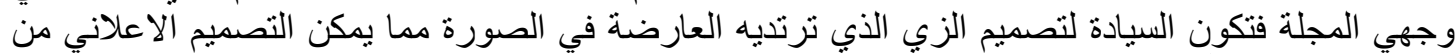

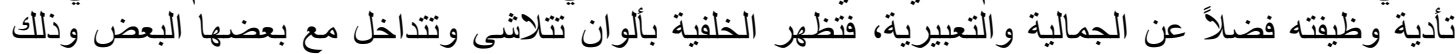

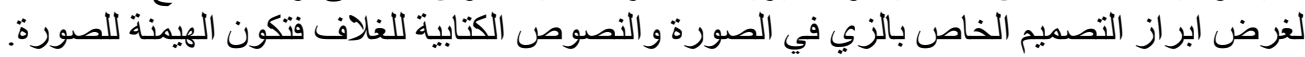

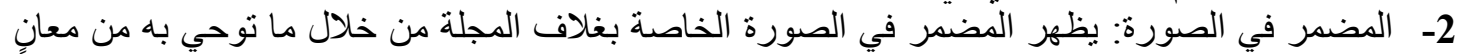

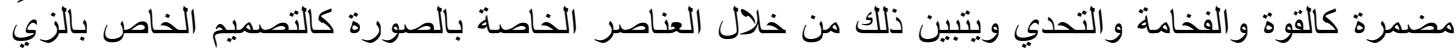

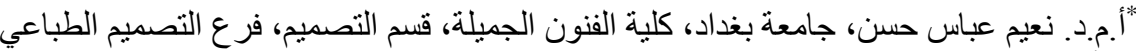

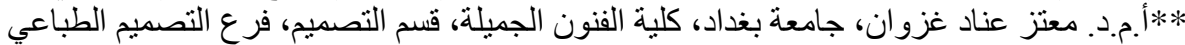

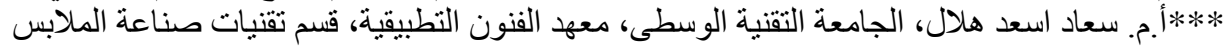

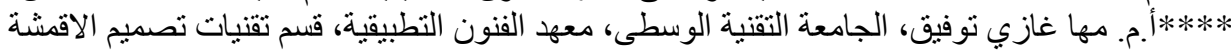

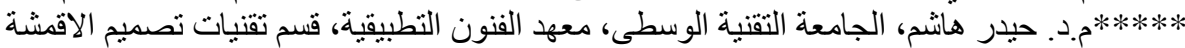




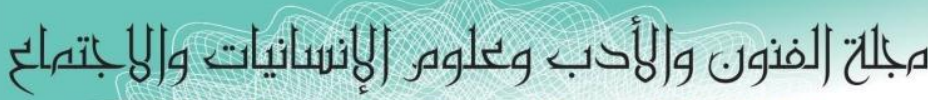
Journal of Arts, Literature, Humanities and Social Sciences

ISSN online: 2414 - 3383

ISSN print: 2616 - 3810

أيلول - سبتهبر 2019

(43) العدد)

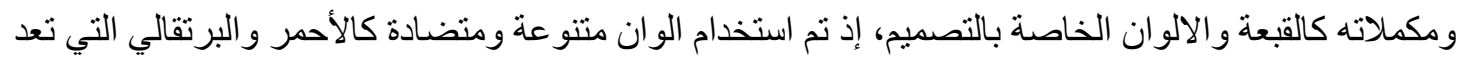

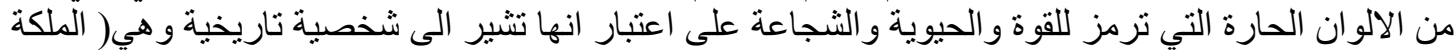

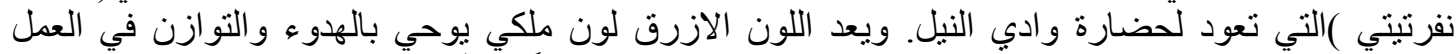

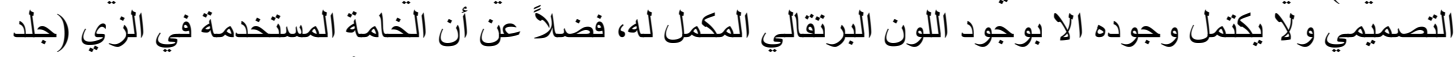

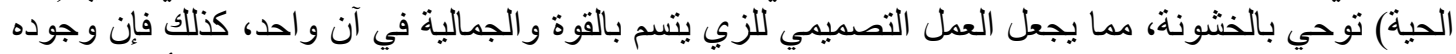

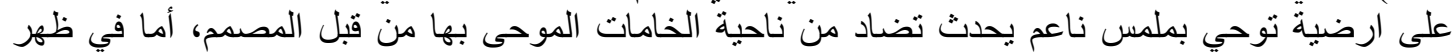

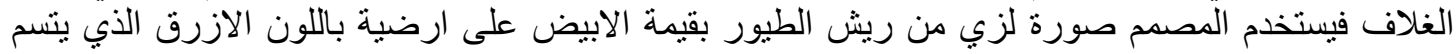

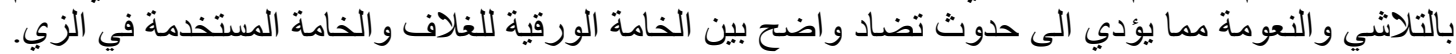

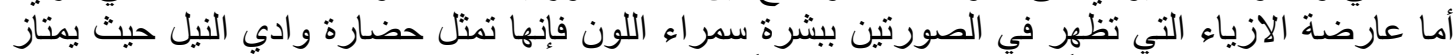

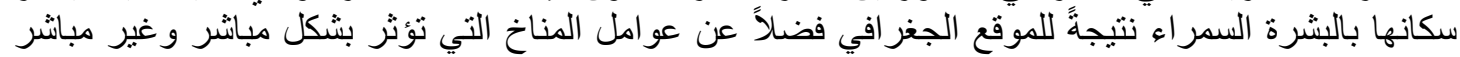
على السكان اللذين يقطنو ها.

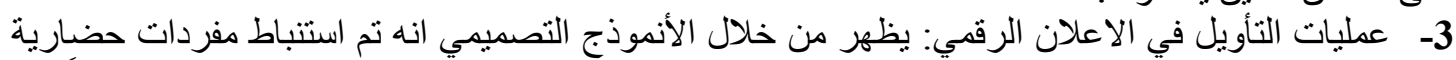

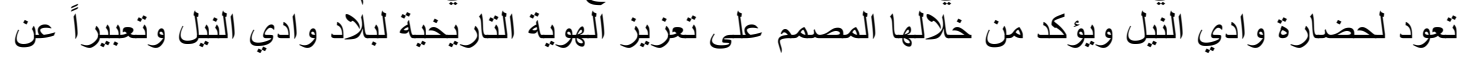

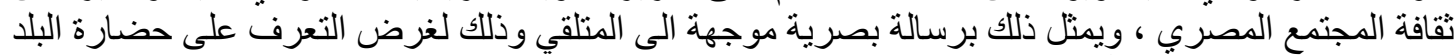

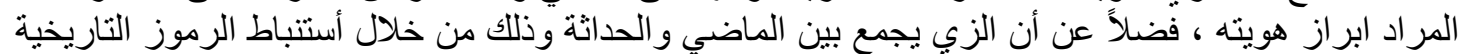

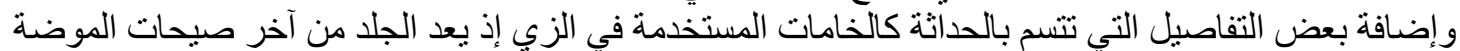

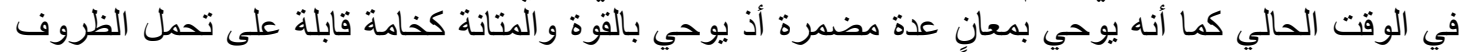

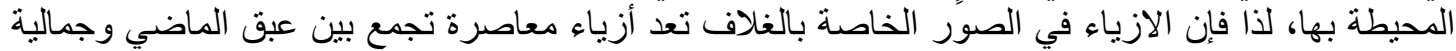
الموضة الحديثة وتقنياتها.

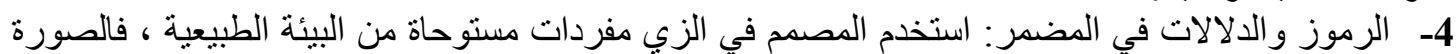

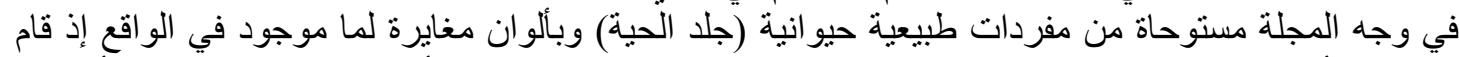

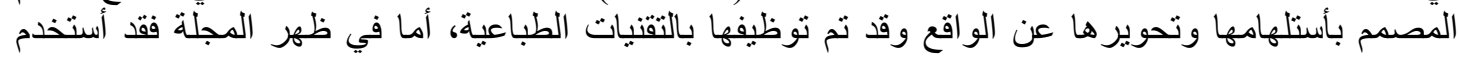

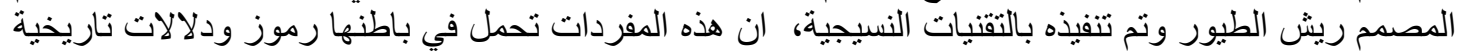

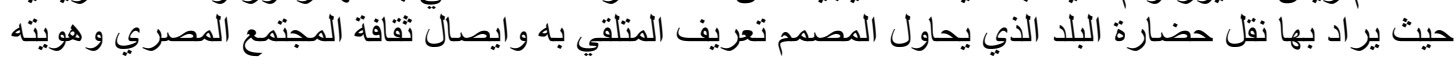

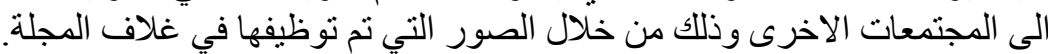

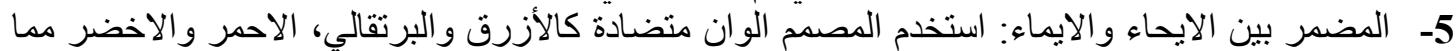

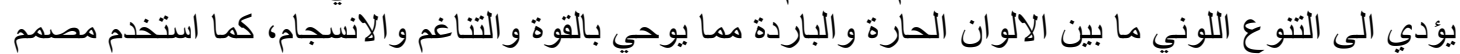

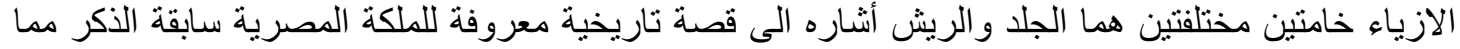

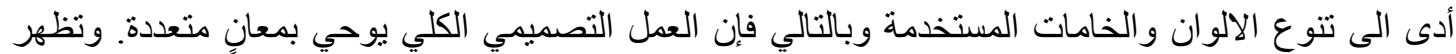

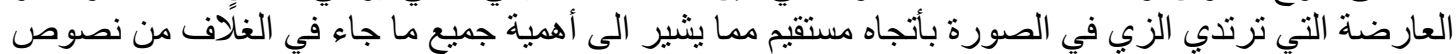

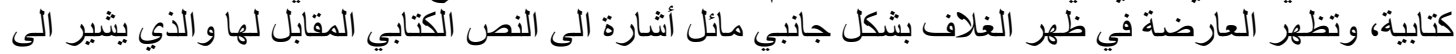

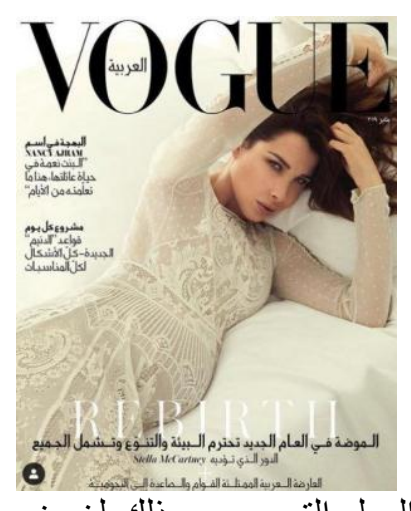

نوع الخامات المستخدمة في الزي. فئري.

عن طريق التقنيات و البرمجيات الرقمية الحديثة مما أدى الى التنوع التقني في العمل التصميمي وذلك لغرضئل 
مبلح الفنون والأدب وعلوه الإنسانيات والإبتماع Journal of Arts, Literature, Humanities and Social Sciences

ISSN online: 2414 - 3383

ISSN print: 2616 - 3810

\section{العدد (43) أيلول - سبتمبر 2019}

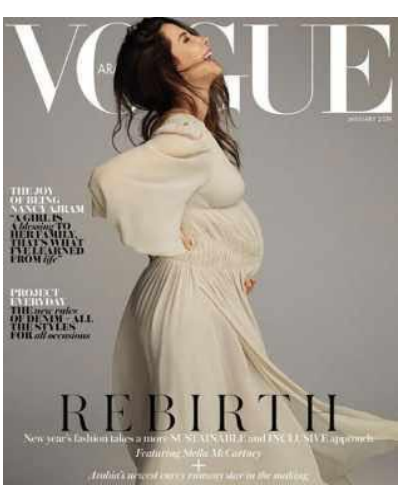

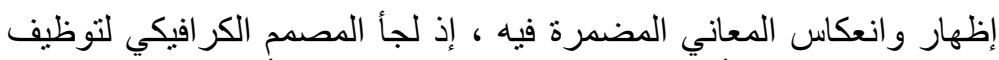

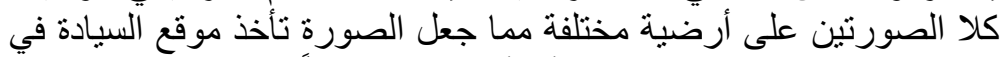

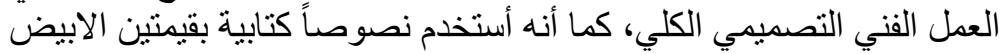

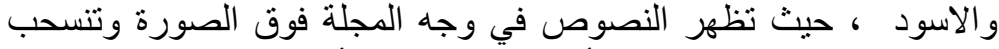

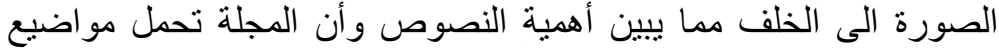

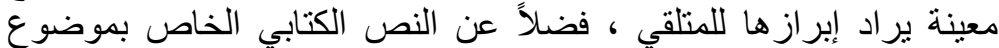

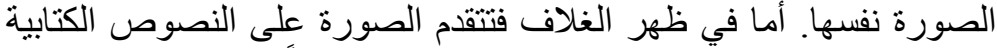

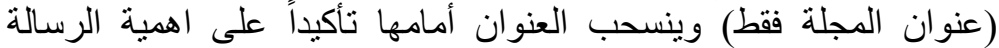

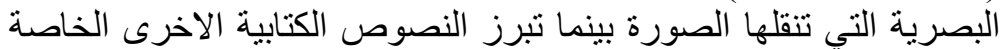
بموضو عات المجلة.

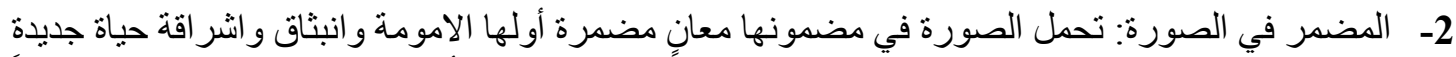

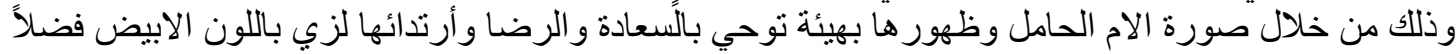

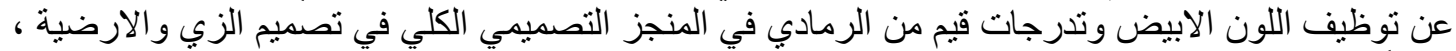

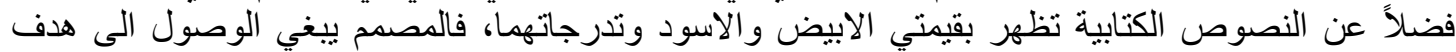

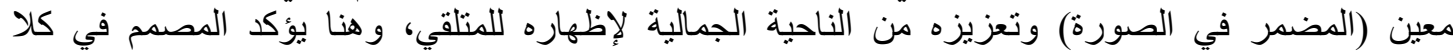
الصورتين على بطن الام موضع الجنين من خلال حركتها مما يساعد المتلقي في عملية تأويل وتفسير المضئ لإكر في الصورة.

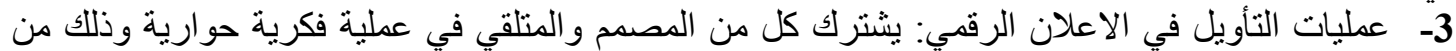

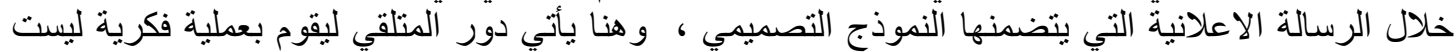

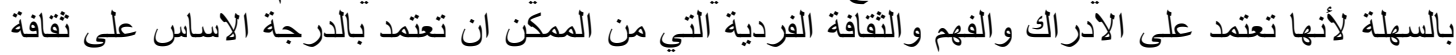

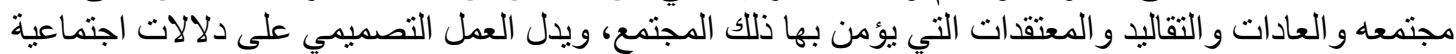

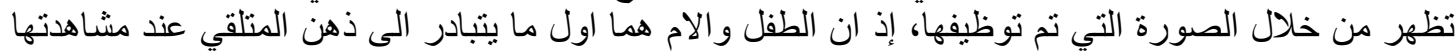

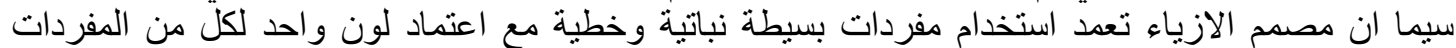

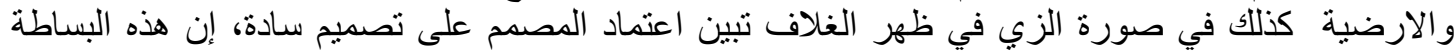

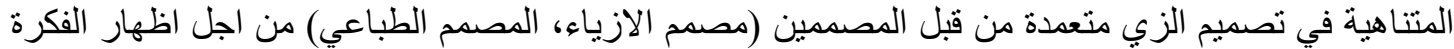

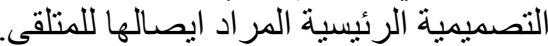

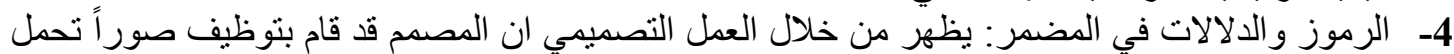

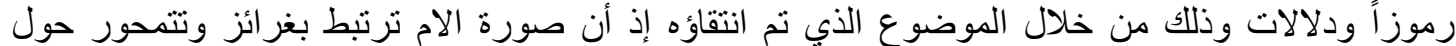

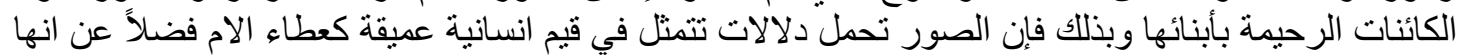

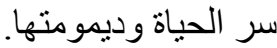

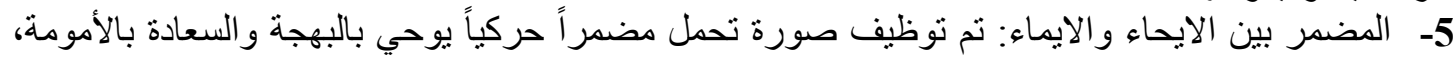

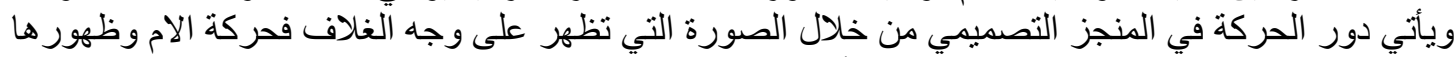

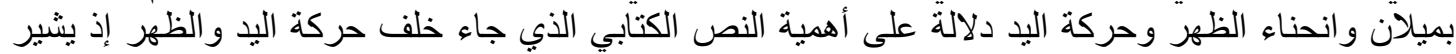

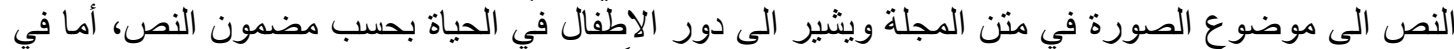

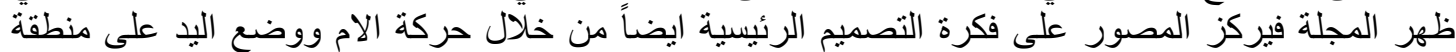

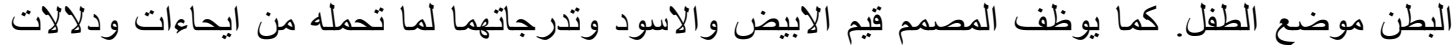

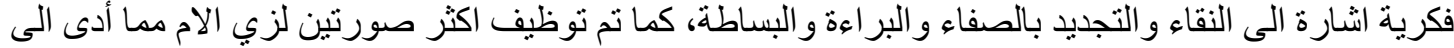

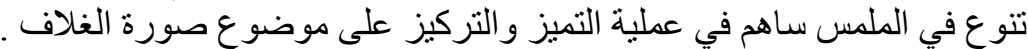

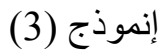
الوصف العام

1- المفردات التصميمية: عناصر تيبو غر افية (صور، الوان نصوص كتابية)، 


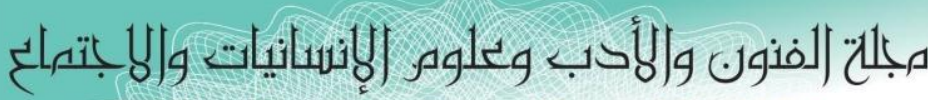
Journal of Arts, Literature, Humanities and Social Sciences

ISSN online: 2414 - 3383

ISSN print: 2616 - 3810

\section{أيلول -سبتمبر 2019}

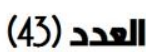

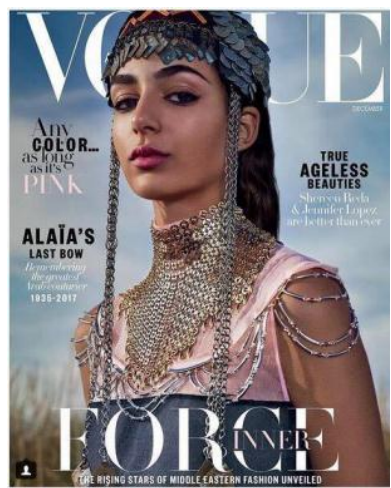

2- الالوان المستخدمة: الابيض والاسود وتدرجاتهما، الاصفر 3-الاستخدام الوظيفي: غلاف مجلة الإنة

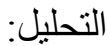

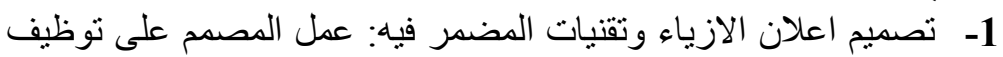

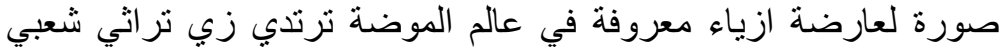

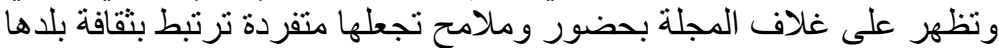

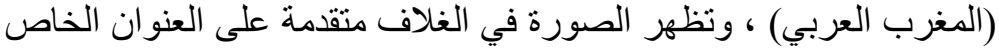

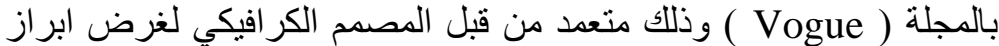

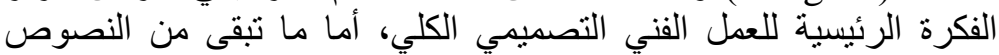

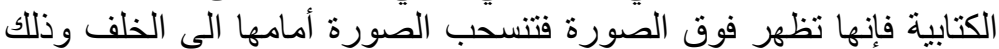

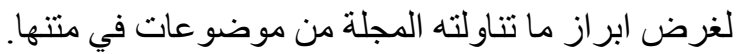

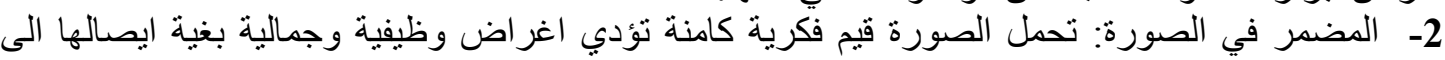

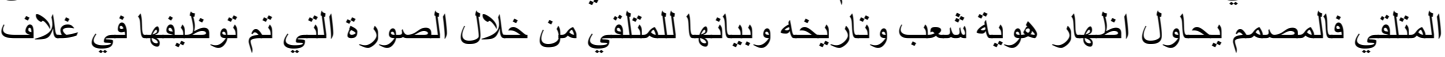

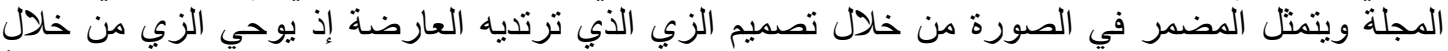

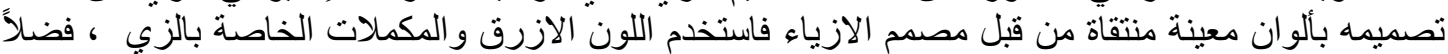

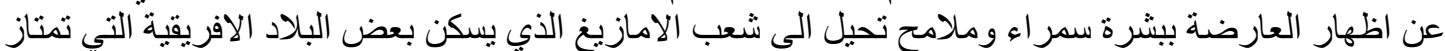

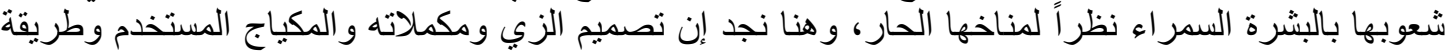

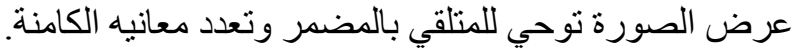

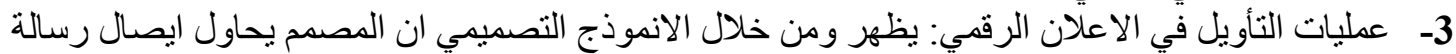

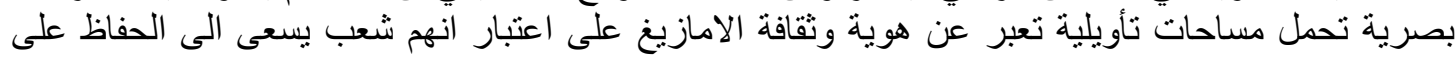

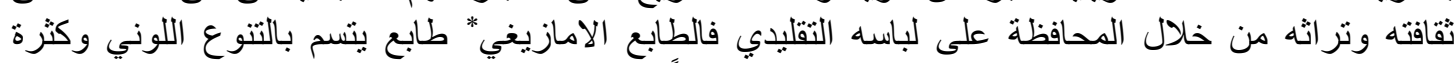

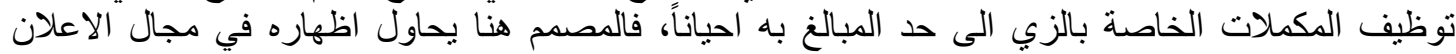
الرقمي لغرض ايصال رسالته الى الزئل المتلقي.

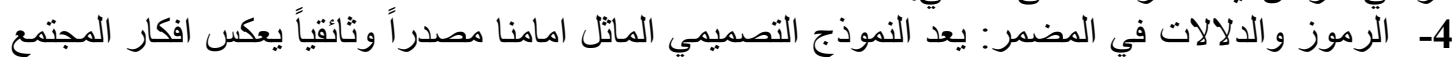

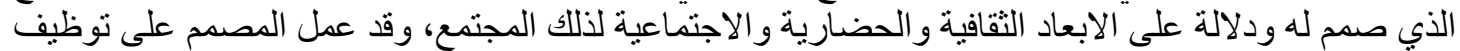

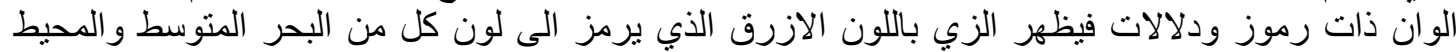

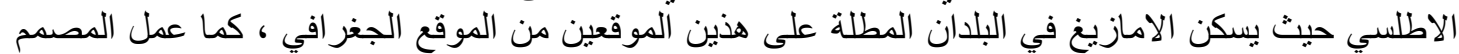

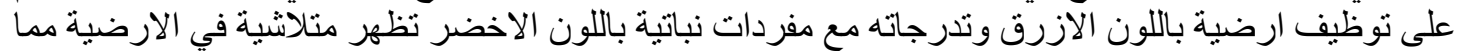

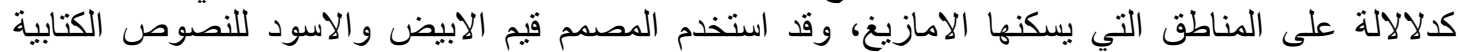

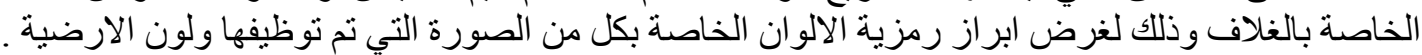

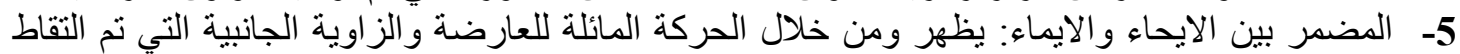

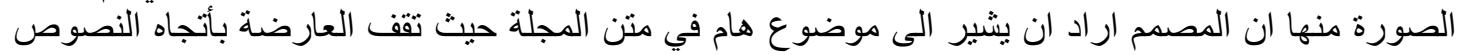

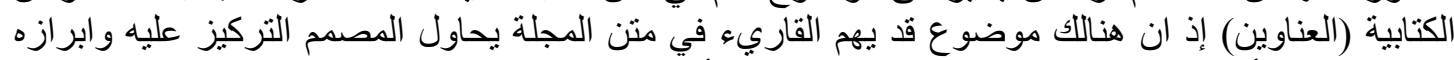

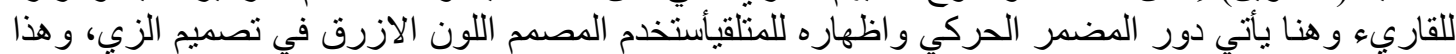

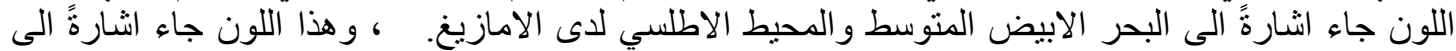

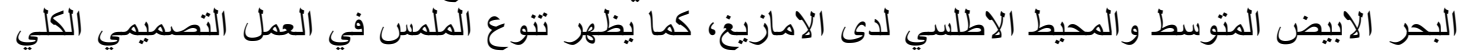

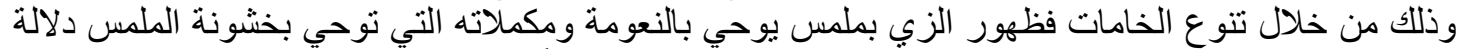

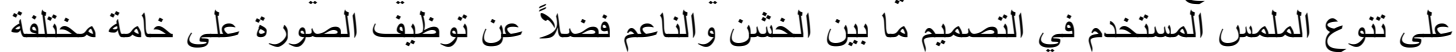
(الورق المصقول) تمناز بالنعومة.

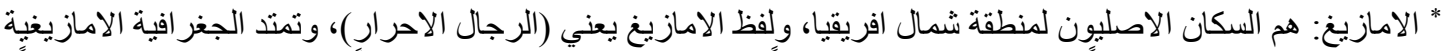

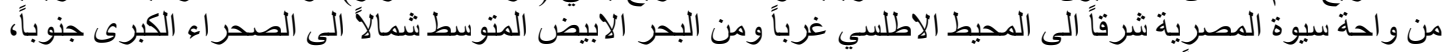

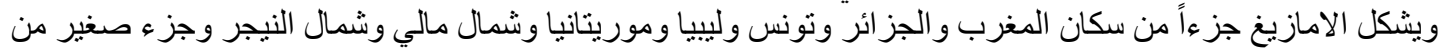
ar.wikipedia.org غرب مصر الجزان 


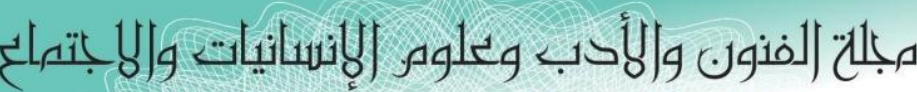

Journal of Arts, Literature, Humanities and Social Sciences

ISSN online: 2414 - 3383

ISSN print: 2616 - 3810

\section{العدد (43) أيلول - سبتمبر 2019}

نتائج البحث ومناقنتها:

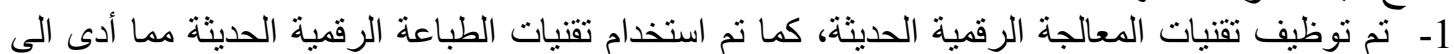

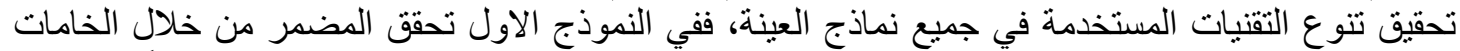

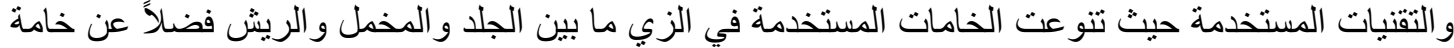

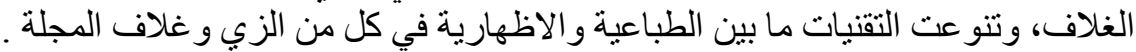

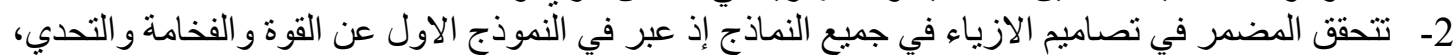

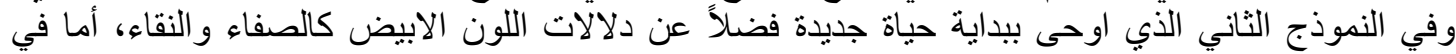

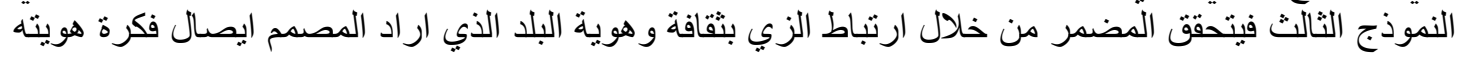

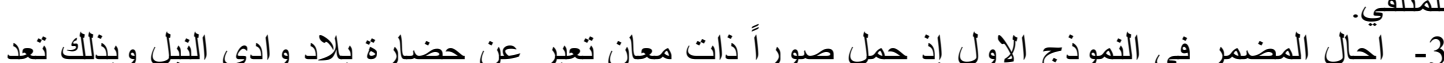

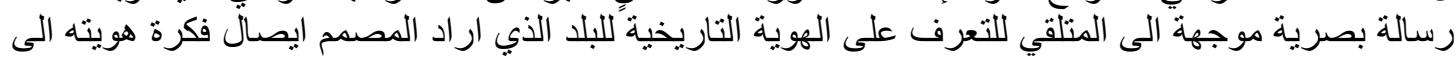

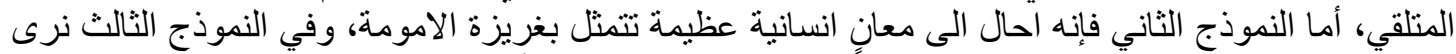

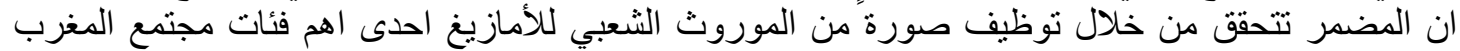

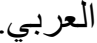

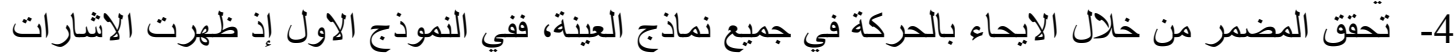

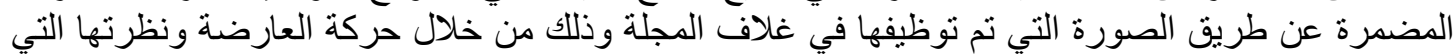

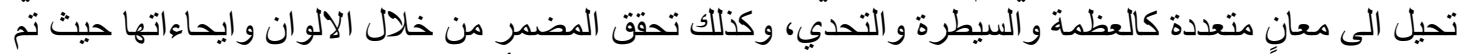

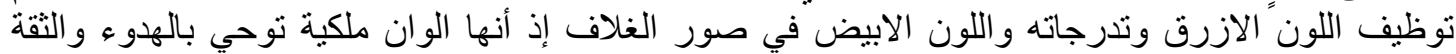

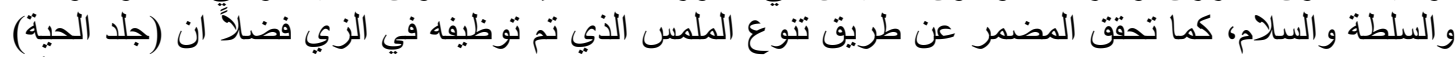

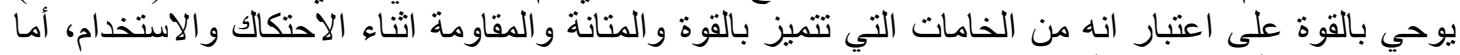

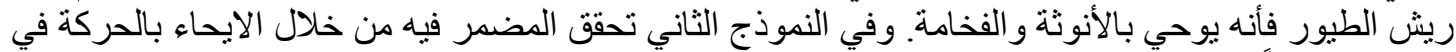

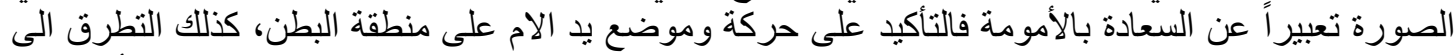

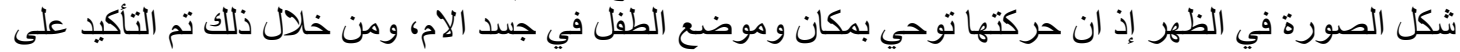

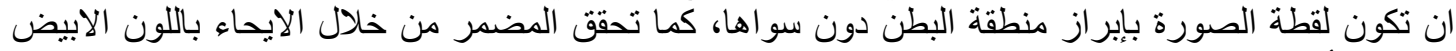

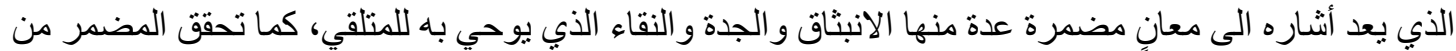

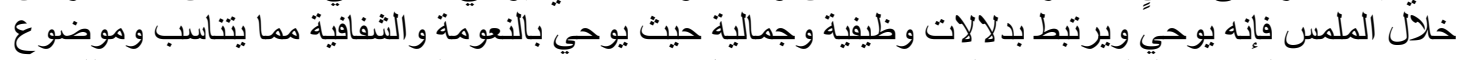

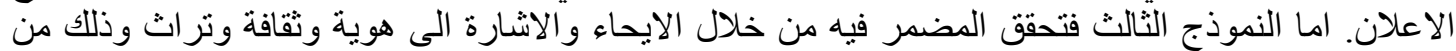

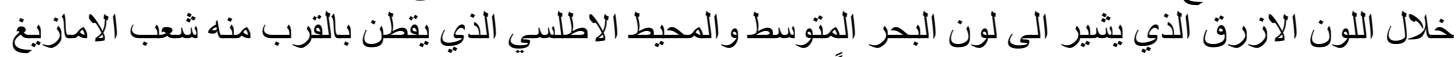

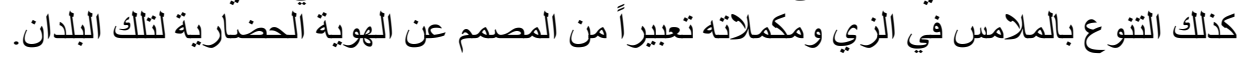

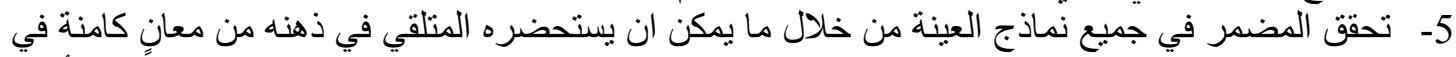

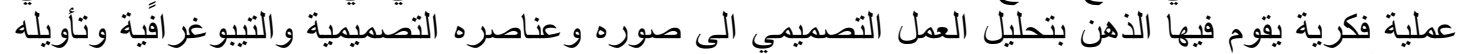

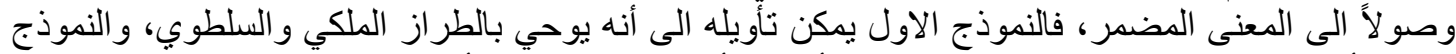

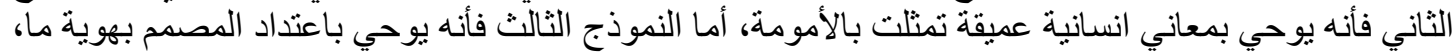

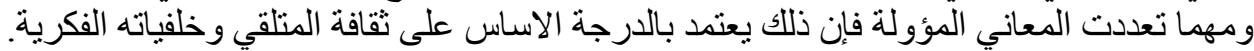

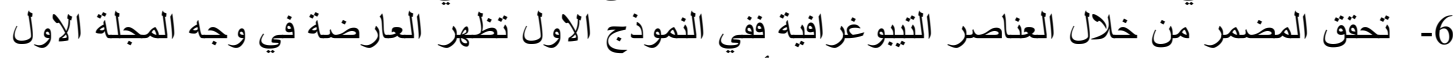

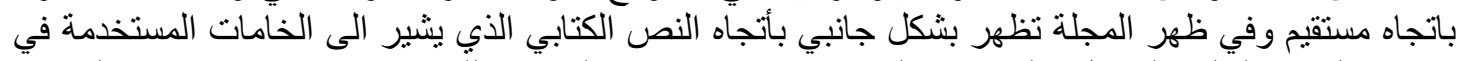

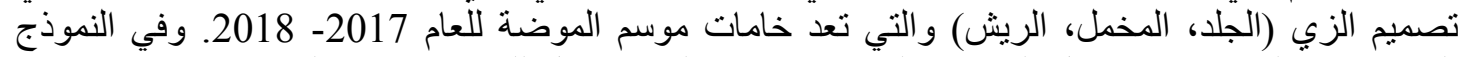

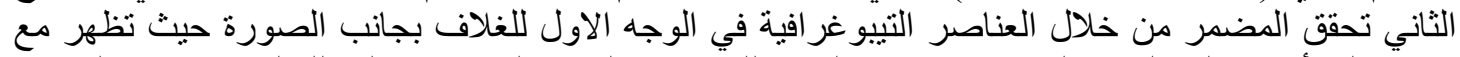

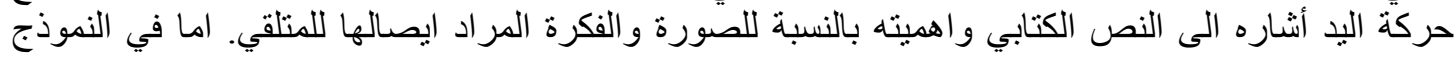

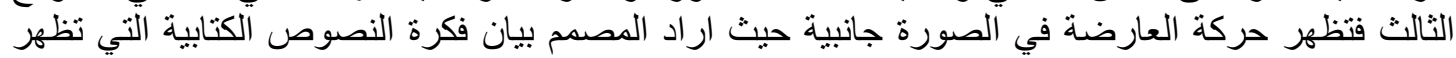




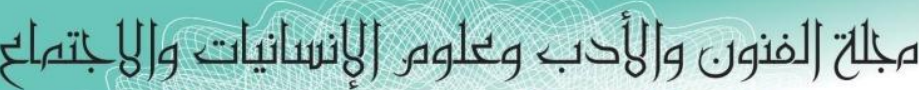

Journal of Arts, Literature, Humanities and Social Sciences

ISSN online: 2414 - 3383

ISSN print: 2616 - 3810

\section{العدد (43) ايلول - سبتمبر 2019}

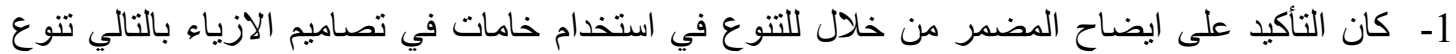

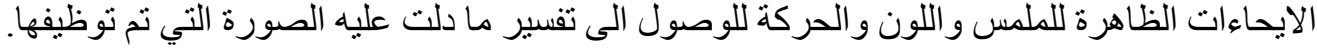

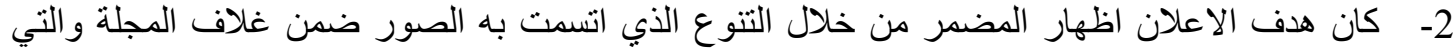

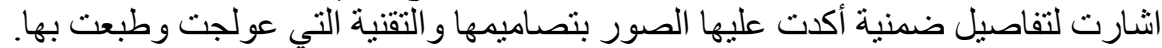

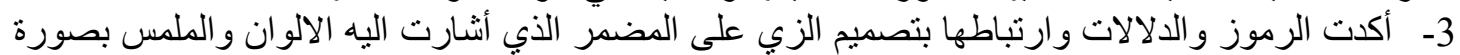

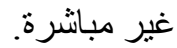
4- ان للتنوع الحضاري والموروث الشعبي دوره في تعزيز الفهم وتفسير الدلالات المضمرة لتلك التصاميم التي مكنت المتلقي من فلك رموز ها.

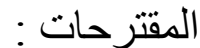
1- القيام بدر اسة الابعاد الوظيفية و الجمالية المضمرة لمؤسسات حكومية ، اوشركات خاصة .

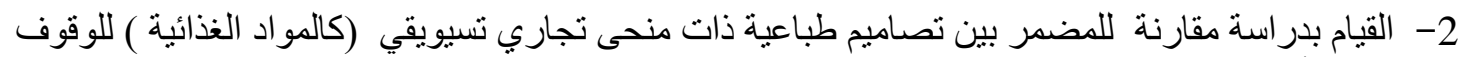

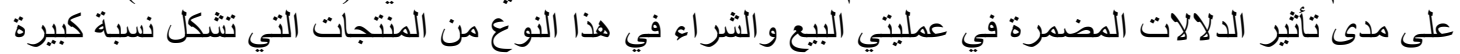

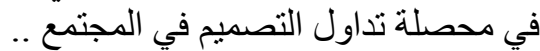

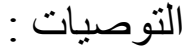
استناداً الى ماتقدم توصي الباحثتان بمايلي :

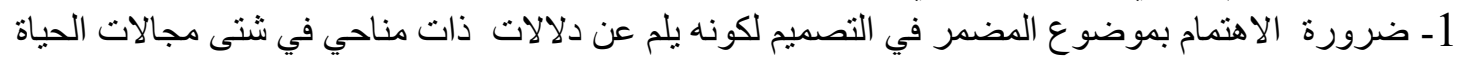

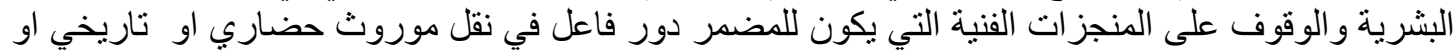

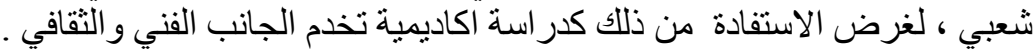

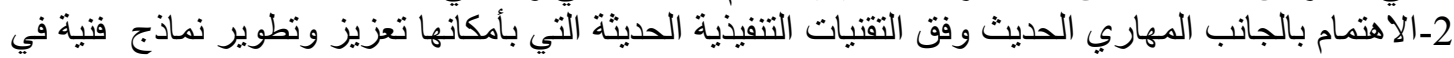

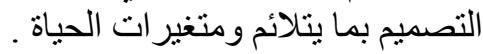

\section{References}

1- Ibn Manzoor Jamal al-Din Muhammad ibn Makram al-Ansari, San Arabs, Volume IV, I 1, Beirut, Dar Sader, 1990.

2- Ann Ober Seefeld, Spectator School, Translation: Hamada Ibrahim et al., Academy of Arts, Center for Languages and Translation, Supreme Council of Antiquities Press, Cairo, d.

3- Andro Edgar, Peter Sayed Goick, Encyclopedia of Cultural Theory, National Center for Translation, Translation of Hanaa El Gohary, Mohamed El Gohary, 1st Floor, 2009.

4- Pierrero. Al-Sumayya, TR, Antoine Abou Zeid, 1st Floor, Oweidat Publications, Beirut, Paris, 1984.

5- Jean Bertlemy, Research in Aesthetics, Translation, Anwar Abdel Aziz, Dar Nahdet Misr, Cairo, 1970.

6- Jameel Solidia, Philosophical Dictionary, Vol. 1, Lebanese Book House, Beirut, 1982.

7- Jillin Wilson, Performing Arts Psychology, T. Shakir Abdulhamid, monthly series of books published by the Council for Culture, Arts and Letters, Kuwait, 2000.

8- Al-Hakim, Radhi, Philosophy of Art by Susan Langer, 1st Floor, House of Cultural Affairs for Printing and Publishing, Baghdad, 1986. 


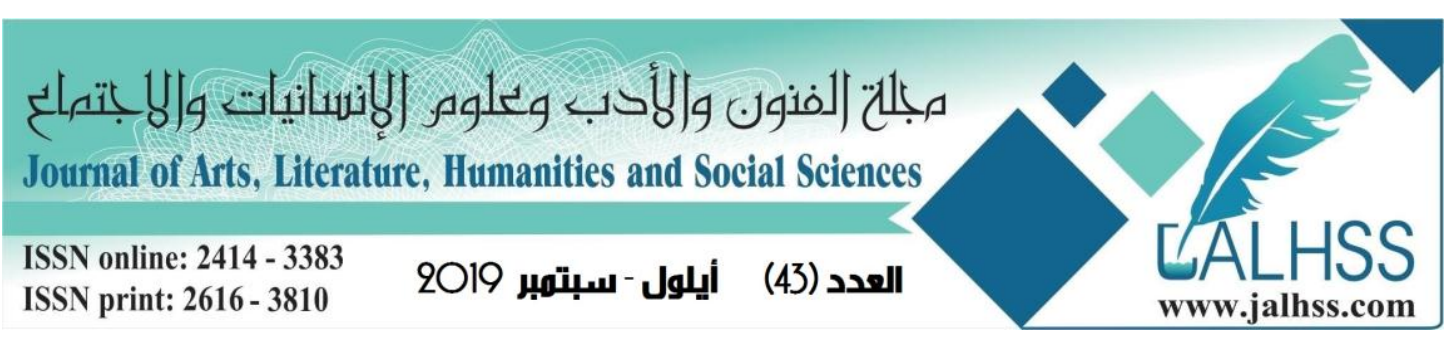

9- Didi, Abdel Fattah. Behavior and Perception, Introduction to Psychology, i 1, Anglo-Egyptian Library, 1972.

10- Robert Scott Gillam, Fundamentals of Design, 3rd floor, Tr .: Abdelbaki

Mohamed Ibrahim and Mohamed Mahmoud Youssef, Dar Al Nahda for Printing and Publishing, Egypt, 1994.

11- Riad Abdel Fattah, Training in Fine Arts, Dar Al Nahda Al Arabiya, 1st Floor, Cairo, 1984.

12- Sami Abdul, Hamid, the rhythm of the theater performance and the response of his audience, Asfar Magazine, No. 15, 1993.

13- Shuja Muslim, Al-Ani, Art Construction in the Arabic Novel in Iraq, Description and Building of the Place, House of General Cultural Affairs, Ministry of Culture and Information, Baghdad, 2000.

14- Taher, Abdul Muslim, The Genius of Image and Place, Expression, Interpretation, Criticism, 1st Floor, Dar Al-Shorouk for Publishing and Distribution, Jordan, Amman, 2002.

15- Al-Adhari, Tariq Abdul-Kadhim, Expressive Theater, Al-Kindi Publishing House, Jordan, 2003.

16- Amer Ibrahim Qandilanji, Encyclopedic Dictionary of Information Technology and Internet, 1st floor, Al-Masirah Publishing and Distribution, 2003.

17- Abdullah Mohammed Al-Ghadami, Cultural Criticism Reading in the Harmony of Arab Culture, 3rd edition, Arab Cultural Center, Morocco, 2005.

18- A number of authors, Simia Prague for theater, translated by Omer Korean, publications of the Ministry of Culture, Damascus, 1997.

19- Akil Mahdi, in the structure of the theater, Baghdad: Ahmed Press, b.

20- Omar Wasfi Aqili, Qahtan Bader Abdali, Hamad Rashed Al Ghadeer, Principles of Marketing (Integrated Entrance), Darzahran Publishing and Distribution, Amman, 1996.

21- Awad Ali, the possibilities of the text system - the presentation system, Amman Magazine, issued by the Greater Amman Municipality, No. (75), 2001,.

22- Al-A'asam, Abdul-Amir, The Philosophical Term of the Arabs, Study and

Realization of Publications of the Arab Thought Library, Baghdad, 1984.

23- Kayed, Amr, Rhythm in Fine Art, Journal of Education, No. 77, 1986 ,.

24- Catherine Kerberat Orikuni, Al-Mudamar, Translation by Rita Khater, 1st Floor, Arab Organization for Translation, Beirut, 2008.

25- Cork Jacob, Language in Modern Literature - Modernity and Experimentation, Translated by Leon Joseph and Aziz Emmanuel, Freedom House for Printing, Baghdad, 1989.

26- Ferdinand Sausser, Lessons in General Linguistics, Translated by Yoel Joseph, Mosul: Books and Printing House, 1988.

27- Philippe Blanche, Deliberation from Oatesen to Fogman, Ter Saber Habasha, 1st Floor, Al-Hiwar Publishing and Distribution, Syria, 2007.

28- Mohammad, Azzam, Criticism and Significance Towards a Semiotical Analysis of Literature, Ministry of Culture, Syrian Arab Republic, Damascus, 1966, 


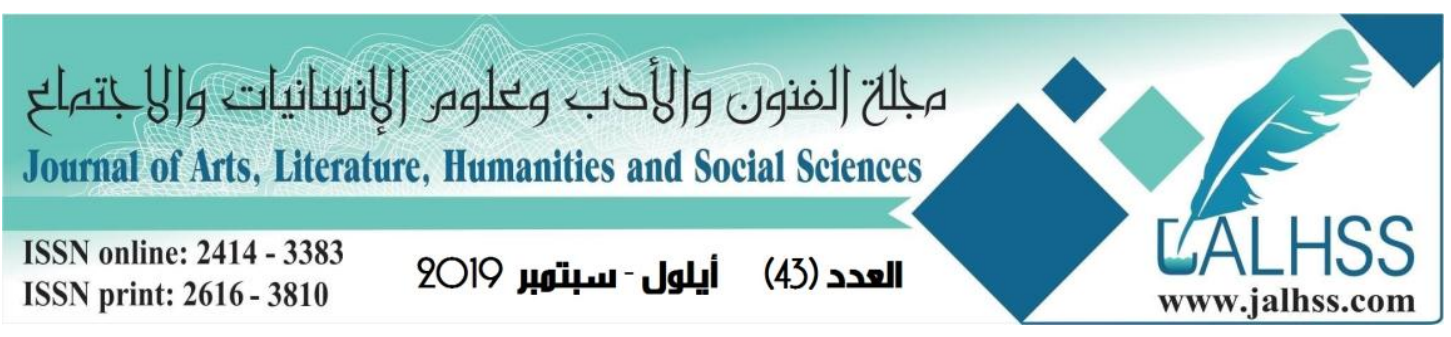

29- Mustafa Nassef: Theory of Tawil, Literary and Cultural Club, Jeddah Press, Saudi Arabia, 1st floor, 2000.

30- Mahmoud Okasha, Discourse Analysis in Theory of Language Events - An Empirical Study of the Methods of Pilgrimage and Persuasion, 1st Floor, Cairo, University Press, 2013.

31- Malas, Mohammed bin Yacoub, on the artistic output of children's journalism, Children's Culture Affairs House, Baghdad, 1984.

32- Henry Bergson, Thought and Moving Reality, Translation, Sami Al-Droubi, AlInshaa Press, Damascus, b. T.

34- Hegel, Frederick, Symbolic Art, Translated by: George Tarabishi, Dar Al-Taleea for Printing and Publishing, Beirut, 1st floor, 1978.

35- Wolfgang, Ayers, Partial Art and Absolute Tawil, d. Muhannad Younis, Foreign Culture, House of Cultural Affairs, Baghdad, No. 3, Year 13, 1992.

36- Noel,G.P., Urban Society,Thomas and Crowell Co.,New York, 1986.

2-Bonta, Juan Pablo: notes for a theory of meaning in design, in Broadbent, Bunte and jancks signs, symbols and Architecture, John Willy, and sons, 1980, p248.

3https://qafilah.com/ar/\%D8\%A7\%D9\%84\%D8\%A5\%D9\%8A\%D9\%85\%D8\%A7\% D8\%A1/

-37 Ed Gecor Kot, deliberations and the implicit meaning, Ter Abdel Rahman

Boudraa, article published on the Center's website Ibn Abi Al Rabie for Linguistic and Literary Studies// www.assebti .ma htt:

38- https://ar.vogue.me/\%D9\%84\%D8\%A7\%D9\%8A\%D9\%81-

\%D8\%B3\%D8\%AA\%D8\%A7\%D9\%8A\%D9\%84/\%D8\%AD\%D8\%B6\%D8\%A7\%D8\%B1\%D8\%A9 $1 \% \mathrm{D} 9 \% 87 \% \mathrm{D} 9 \% 84-$ 
مبلحة لفنون والأدب وعلوه الإنسانيات و|لابتهماع Journal of Arts, Literature, Humanities and Social Sciences

ISSN online: 2414 - 3383

ISSN print: 2616 - 3810

أيلول - سبتمبر 2019

\section{الملحق}

استمارة محاور تحليل العينات بصيغتها النهائية

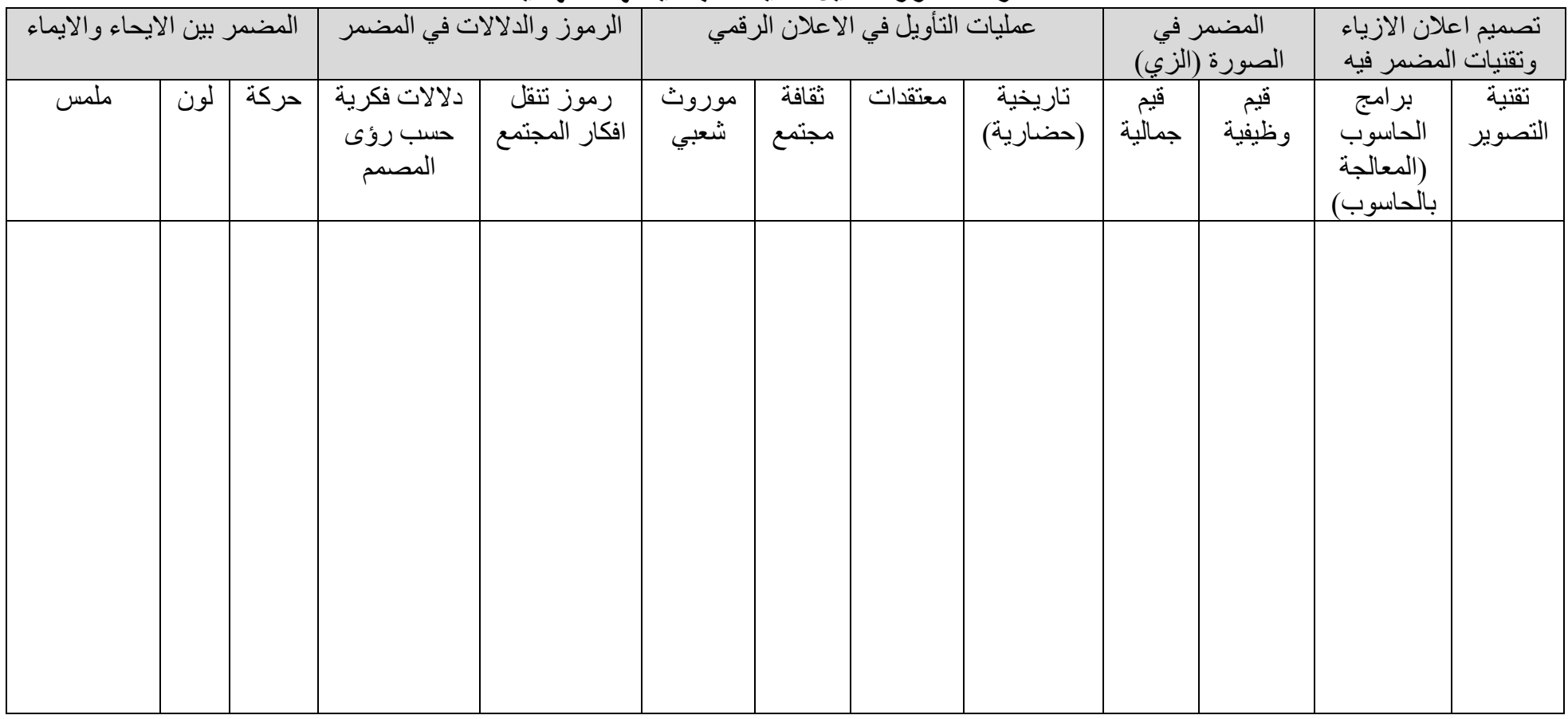

